Article

\title{
An Agricultural Products Supply Chain Management to Optimize Resources and Carbon Emission Considering Variable Production Rate: Case of Nonperishable Corps
}

\author{
Mohammed Alkahtani ${ }^{1, *} \oplus$, Muhammad Omair ${ }^{2} \oplus$, Qazi Salman Khalid ${ }^{2}\left({ }^{\circ}\right.$, Ghulam Hussain ${ }^{3}$ \\ and Biswajit Sarkar ${ }^{4, *(1)}$ \\ 1 Department of Industrial Engineering, College of Engineering, King Saud University, \\ P.O. Box 800, Riyadh 11421, Saudi Arabia \\ 2 Department of Industrial Engineering, Jalozai Campus, University of Engineering and Technology, \\ Peshawar 25000, Pakistan; muhamad.omair87@gmail.com (M.O.); qazisalman@uetpeshawar.edu.pk (Q.S.K.) \\ 3 Faculty of mechanical engineering, GIK Institute of Engineering Sciences \& Technology, Topi 23460, Pakistan; \\ gh_ghumman@hotmail.com \\ 4 Department of Industrial Engineering, Yonsei University, 50 Yonsei-ro, Sinchon-dong, Seodaemun-gu, \\ Seoul 03722, Korea \\ * Correspondence: moalkahtani@ksu.edu.sa (M.A.); bsarkar@yonsei.ac.kr or bsbiswajitsarkar@gmail.com (B.S.)
}

Received: 18 September 2020; Accepted: 11 November 2020; Published: 20 November 2020

\begin{abstract}
The management of the man-machine interaction is essential to achieve a competitive advantage among production firms and is more highlighted in the processing of agricultural products. The agricultural industry is underdeveloped and requires a transformation in technology. Advances in processing agricultural products (agri-product) are essential to achieve a smart production rate with good quality and to control waste. This research deals with modelling of a controllable production rate by a combination of the workforce and machines to minimize the total cost of production. The optimization of the carbon emission variable and management of the imperfection in processing makes the model eco-efficient. The perishability factor in the model is ignored due to the selection of a single sugar processing firm in the supply chain with a single vendor for the pragmatic application of the proposed research. A non-linear production model is developed to provide an economic benefit to the firms in terms of the minimum total cost with variable cycle time, workforce, machines, and plant production rate. A numerical experiment is performed by utilizing the data set of the agri-processing firm. A derivative free approach, i.e., algebraic approach, is utilized to find the best solution. The sensitivity analysis is performed to support the managers for the development of agricultural product supply chain management (Agri-SCM).
\end{abstract}

Keywords: agri-supply chain management; variable production rate; optimal resources; imperfect production; eco-efficient production

\section{Introduction}

Owing to the escalating awareness of resource depletion, climate change, and increasing population, firms in the agriculture domain need to redesign their current supply chain models by taking economic and environmental impacts into account [1]. The life cycle of products held in inventory and processing produce a major concern of perishability among agri-products throughout the supply chain. Therefore, replenishment strategies, product supply, and processing indicators are crucial to consider in the research models. The global market for perishable goods, such as refrigerated products and prepared 
meals, is growing due to changing lifestyles and overall decreasing tariffs. Owing to their common fragility and limited lifetime, handling those goods is far more complex and includes much higher risks compared to non-perishable products [2]. However, this work deals with the sugar processing from sugarcane as a raw material in local industry with outsourcing operation as a non-perishable product because of the long life of raw sugarcane. Also, the supply chain considers a small portion of the whole network, i.e., a single sugar processing firm with a single outsourcing vendor.

It is evident that the incidence of the uncertain factors is unforeseeable, which may induce a number of decision-making mistakes through the application of a traditional supply chain, thus incurring a high cost and unclean production environment [3]. Moreover, variable demand alters the former assumptions in which demand follows a discrete known distribution for different agri-products [4]. To cover up the deficit caused by the positive and negative surges in agri-product demand, an intelligent variable production model should be integrated within the supply chain. Moreover, controllable production will result in cleaner production as it will optimize the resources without losses and wastes. Because it is estimated that, by 2050, the overall production of food should increase by approx. $70 \%$ in order to feed the increasing global population [5]. Hence, the best utilization of resources in a supply chain is a key factor for cleaner agri-production.

Production technology has played a vital role in the upgradation agriculture supply chain and has been a limelight for governments and agri-business sectors. In the basic production model, the assumption of constant production rate was observed predominantly. Later on, the variable machine production rate was also included by considering optimal production costs in manufacturing systems. Although variable production rate remained the point of interest for researchers many years ago through its effects on machine tool cost with increasing production rate [6,7]. However, Moutaz Khouja (1995) [8] was among the pioneers to extend the basic production model and consider production rate as a decision variable for the volume flexibility of production. The model suggested the volume-flexibility of manufacturing systems for larger sized lots with a lesser production rate. Moreover, an increased production rate decreases the repeatability [9] of a robot and affects the quality, as discussed by [10].

This research contributes to transforming the idea of an intelligent, green supply chain production into a mathematical model. The aim of the model is to represent tangible analysis of human-machine interaction and imperfect production system in order to optimize use of resources and minimize wastes. The inclusion of carbon emission cost as an eco-efficient attribute along with the variable production rate, satisfying agribusiness firms' demand, is also a limelight of this work, which is hardly observed in previous literature. Further, the impact of this work is extended to quantify production loss due to improper human-machine correspondence. The investigation provides a plan of action for agri-product manufacturing managers to invest in favor of optimized production with effective resource utilization, which ultimately leads to less rejection in a production environment.

The article is structured in a well possible way i.e., background and challenges to the agricultural supply chain management (agri-SCM) are discussed in this section. In Section 2, the literature is well represented from author contributions, which are presented in consideration of the research gap. Section 3 covers the detailed mathematical formulation of controllable production rate, labor-machine interaction, inventory management, and eco-friendly agri-SCM. The solution method, i.e., algebraic approach application, is also given in Section 3. Afterwards, Section 4 deals with the numerical experiment, which consists of the required data for performing the experiment using the proposed SCM model. The numerical results are also explained and illustrated significantly in Section 4 along the sensitivity analysis of the SCM model to mathematically check the significant cost parameters with respect to the total cost are also performed. In Section 5, conclusion of the research study is discussed.

\section{Research Reviews}

In a cleaner production environment, prime attention is given to the reduction of production and associated costs. Fluctuation in agri-products' raw materials, fuel prices and falling sale rates drive 
the agribusiness firms to incorporate technologies and processes which controls expenses. In order to fulfill the requirements of the future generations, the agri-product supply chain should eliminate existing wastefulness and lay emphasis over green defective free production. Such resource waste elimination requires decision assisted tools that covers intrinsic characteristics of an agri-based product. Furthermore, a green agri-product supply chain needs more than only economic validation objective (profit), thus, it should be also able to handle eco-efficient objective. Hence, the decision assisted tool requires the evaluation of both the economic and environmental aspects simultaneously. For this purpose, mathematical optimization is fairly viable to discover best values from the domain and set a better trade-off for managerial insights [11], and for establishing eco-efficient results-based system [12]. The detailed author contributions are given in Table 1.

In the agricultural supply chain, most of the work is found in the logistic of food supply [13], food safety [14], and imperfect information system. As there is a desirable need to encounter the requirements of lean manufacturing, supervision of scraps and reworks due to the significant concerns for production systems [15-17]. In this aspect, Agri-SCM should be integrated with imperfect and green production. From the perspective of solution methodology, Minjung Kwak (2015) [18] recommended a mixed-integer linear-programming (MILP) model that optimizes the re-manufacturing plan in order to validate both the environmental and economic benefits of products. Some researchers have taken carbon footprint into account for development of cleaner production SCM models. For instance, Xiao et al. (2016) [19] optimized SCM cost via minimizing carbon footprint of both the retailers and manufacturers. In this domain, Chia-Chin Wu and Ni-Bin Chang (2004) [20] presented a grey theory model for uncertain conditions which reflects environmental impact by taking the production planning tax into account. Wang et al. (2011) [21] established a bi-objective model that evaluates the associated costs with environmental plans along a green SCM. Additionally, [22] suggested an electricity monitoring-system that considers a multi-objective linear-programming model taking carbon footprint into account by electricity usage as a supply of energy. As referred earlier, (Banasik (2019) [1]) that work included model development of an uncertain eco-efficient supply chain, however, their model lacks integration of imperfect production.

The effect of the workers' cost on production and inventory is a significant aspect to cleaner production and can be analyzed in numerous models. Most of the researchers, i.e., [23-25] studied an imperfect production environment to assist the managers in dealing with poor quality products. Though, very few studies have analyzed the cause to reduce an imperfect production in the setup. A number of factors that affect the production flow and cause imperfection include reworks, rejections, and scraps etc. The management and planning of imperfect production in the model provide a cleaner production int the system and wastes are managed with modeling of the imperfect production [26]. In another study, Sarkar et al. (2018) [27] developed a global sustainable supply chain model with constant production rate having short-term production period in which synchronize mechanism is used to set the cycle time for each production stage. Tiwari et al. (2018) [28] presented a green production quantity model with random imperfect quality products, service level constraints, and failure in reworking. These are depending on the combined efficiency of the machines and workers. Further, the role of controllable production is effective in dealing with imperfect production.

Moutaz Khouja and Abraham Mehrez (1994) [29] proved the deterioration in quality of product with increase in production rates in an economic production inventory model. He reassessed Rosenblatt [30] work with an assumption of quality function. In another study, Khouja et al. [31] further extended his earlier model by assuming that the production rate had a probability to shift production system from in control to the out-of-control state. Later on, Somkiat Eiamkanchanalai and Avijit Banerjee (1999) [32] advanced the work and established model that determines both the optimal production cycle length and variable production rate for a single item. Giri et al. (2005) [33] introduced a flexible production rate EPQ model that addressed the issue of higher stress level of the human-machine interaction with the increase of production rate. In this EPQ model, the unit production cost was stated as a function of the production rate, under general failure and overhaul time. Moreover, [34] presented an EPQ 
model where the production cycle consisted of multiple runs at various production rates. The author revealed that the production rates should take values between demand rate and production rate that reduces the production cost. Later on, Shib Sankar Sana (2010) [35] studied unit production cost as a function of product reliability and variable production rate in imperfect production system. Giri et al.'s (2005) [33] model was later extended with stochastic demand by [36], sampling in inspection by [37], and stochastic repair time by [38]. Also, Zanoni (2014) [39] examined the case of energy consumption in two stage production system where production depends on the variable production rate. 
Table 1. Author Contribution.

\begin{tabular}{|c|c|c|c|c|c|c|c|c|c|c|c|}
\hline \multirow[t]{2}{*}{ Author(s) } & \multirow[t]{2}{*}{$\begin{array}{c}\text { Two- } \\
\text { Echelon } \\
\text { SCM }\end{array}$} & \multicolumn{2}{|c|}{ Imperfection } & \multicolumn{2}{|c|}{$\begin{array}{l}\text { Production } \\
\text { Rate }\end{array}$} & \multicolumn{3}{|c|}{$\begin{array}{c}\text { Resources } \\
\text { Optimization }\end{array}$} & \multirow[t]{2}{*}{$\begin{array}{c}\text { Eco- } \\
\text { Efficient }\end{array}$} & \multirow[t]{2}{*}{$\begin{array}{l}\text { Agri- } \\
\text { SCM }\end{array}$} & \multirow[t]{2}{*}{ Methodology } \\
\hline & & Scrap & Rework & Constant & Variable & Workforce & Machines & Combined & & & \\
\hline Bansik et al. [1] & $\sqrt{ }$ & & & & $\sqrt{ }$ & & & & $\sqrt{ }$ & $\sqrt{ }$ & $\begin{array}{l}\text { Bi-stage stochastic } \\
\text { programming }\end{array}$ \\
\hline Yasmine et al. [13] & $\sqrt{ }$ & & & $\sqrt{ }$ & & & & & & $\sqrt{ }$ & Analytical method \\
\hline Francesco Zecca [14] & $\sqrt{ }$ & & & & & & & & & $\sqrt{ }$ & Analytical method \\
\hline Pablo Biswas [15] & & $\sqrt{ }$ & $\sqrt{ }$ & $\sqrt{ }$ & & & $\sqrt{ }$ & & & & $\begin{array}{c}\text { Analytical } \\
\text { optimization }\end{array}$ \\
\hline Tayyab [16] & $\sqrt{ }$ & $\sqrt{ }$ & & $\sqrt{ }$ & & & & & & & $\begin{array}{c}\text { Analytical } \\
\text { optimization }\end{array}$ \\
\hline Wang et al. [21] & & $\sqrt{ }$ & $\sqrt{ }$ & $\sqrt{ }$ & & & & & & & $\begin{array}{c}\text { Normalized } \\
\text { constraint method }\end{array}$ \\
\hline S Sarkar [26] & $\sqrt{ }$ & & $\sqrt{ }$ & & $\sqrt{ }$ & & $\sqrt{ }$ & & & & Algebraic Approach \\
\hline Moutaz Khouja [29] & & & & & $\sqrt{ }$ & & $\sqrt{ }$ & & & & Analytical method \\
\hline Martin Linde-Rahr [40] & & & & & & $\sqrt{ }$ & & & & $\sqrt{ }$ & Game theory \\
\hline Sarkar [41] & & & $\sqrt{ }$ & $\sqrt{ }$ & & & & & & & Analytical method \\
\hline Shib Sankar Sana [42] & $\sqrt{ }$ & & $\sqrt{ }$ & & $\sqrt{ }$ & $\sqrt{ }$ & $\sqrt{ }$ & & & & Analytical method \\
\hline Sarkar [43] & $\sqrt{ }$ & $\sqrt{ }$ & $\sqrt{ }$ & $\sqrt{ }$ & & & $\sqrt{ }$ & & & & Algebraic approach \\
\hline Xueli Ma et al. [44] & $\sqrt{ }$ & & & $\sqrt{ }$ & & & & & & $\sqrt{ }$ & Algebraic Approach \\
\hline Proposed research & $\sqrt{ }$ & $\sqrt{ }$ & $\sqrt{ }$ & $\sqrt{ }$ & $\sqrt{ }$ & $\sqrt{ }$ & $\sqrt{ }$ & $\sqrt{ }$ & $\sqrt{ }$ & $\sqrt{ }$ & $\begin{array}{c}\text { Algebraic approach } \\
\text { (SQP) }\end{array}$ \\
\hline
\end{tabular}


Production inventory outsourcing policy was studied by [45] for a firm with Markovian in-house production capacity that faced independent stochastic demand operating with outsourcing operation. Also, Pablo Biswas and Bhaba R Sarker (2008) [15] proposed a manufacturing process whereby finished goods are produced along with a proportion of undesirable defective products and scrap. As the system is not always perfect, some scrap is produced during the manufacturing and/or rework processes. According to Wang et al. (2013) [46], when the outsourcing quantity and wholesale price are decision variables, the competitive contract manufacturer sets a wholesale price sufficiently low to allow both parties to coexist in the market, and the original equipment manufacturer outsources its entire production to contract manufacturer. Bettayeb et al. (2014) [47] presented a risk-based approach for quality control of complex discrete manufacturing processes to prevent massive scraps. The advancement targeted from this work is the proposal of a model, aiming at the quality control allocation of the products and an understandable algorithm to prevent the production of excessive amount of scrap.

This research deals with the agri-product supply chain management (Agri-SCM). Abundant work on variable production models on realistic case scenarios exists. Particularly, most of the research on eco-efficient (reducing carbon emission) supply chain assumes deterministic demands and constant production rate, and hardly flexible productivity is taken into account. Further, technology development urges for intelligent models in which man-machine interactions are optimized in order to attain minimal wastes. Such intelligent models can hardly be seen in the literature. Additionally, to assert an efficient green production through the supply chain, imperfect production plays a vital role to cut down the cost and reduce the consumption of extra resources. Moving forward, it is worth mentioning that no traces related to agri-products supply chain with intelligent eco-efficient model is found. This work contributes to the latest literature by: (1) providing a centralized, two-echelon supply chain model with variable production rates, (2) presenting an intelligent model in which human-machine interactions are optimized, (3) carbon emission cost and imperfect production are integrated with the proposed model to assure a cleaner production environment, and (4) Agri-SCM with deteriorated products is introduced.

\section{Method and Materials}

\subsection{Research Modeling}

This human-machine interface is more significant in the supply chain management of agricultural products. The research contributes to transform the theoretical idea into a mathematical model with an aim to represent the tangible analysis of the imperfect production system in supply chain management. The model is based on Agri-SCM for deteriorated agri-product by considering controllable production rate from the interaction of the human and workers. The flow diagram of the Agri-SCM is illustrated in Figure 1. This research deals with the two-echelon Agri-SCM and covers the agri-food processing firm, where the vendor is involved into few operations because of capacity limitation. The first stage includes the basic food operations, second stage is dedicated to the vendor operations, and the third stage is the finishing stage. The raw material in manufacturing firms is first processed through the basic cleaning operations. Then, the semi-finished parts are outsourced to the vendor firm. The inspection operations are carried out by the vendor, where the parts are sorted as good and defective. In order to compensate for the rejection to meet the required demand, the same quantity of rejections is ordered to manufacture from the first stage of the processing firm. The good agri-products are further delivered to the final stage for further processing and packaging. 


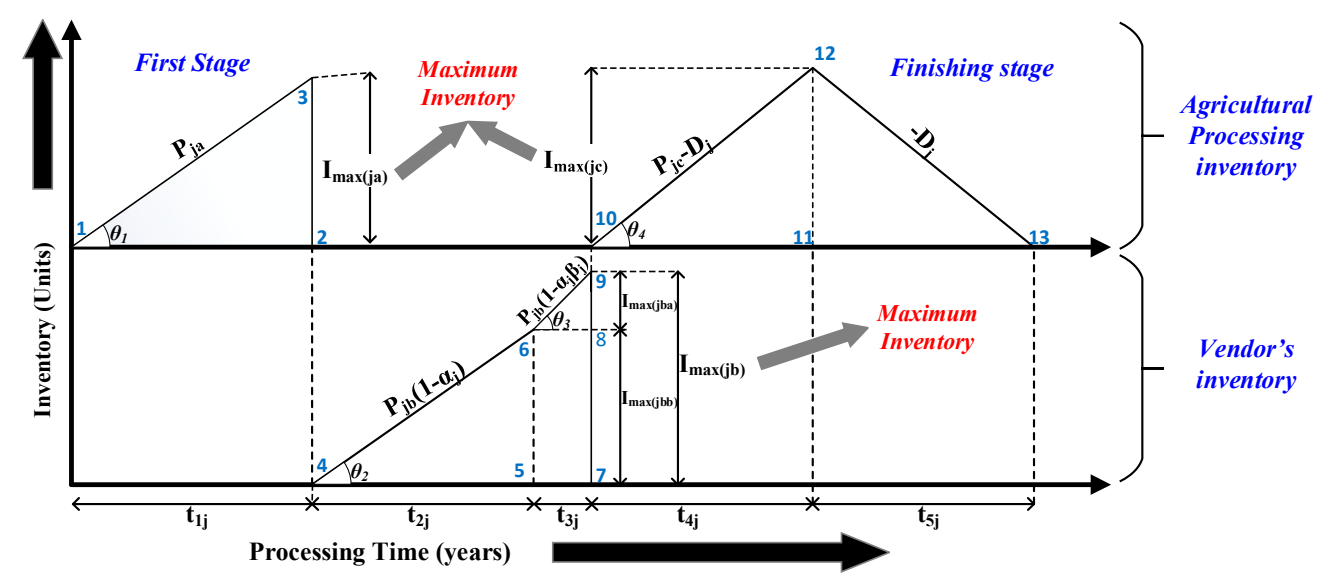

Figure 1. The inventory diagram of the agricultural supply chain management (Agri-SCM).

\subsubsection{Assumptions}

The following assumptions were used for the proposed model.

1. The mathematical model is based on multiple types of agri-product. The constant and variable production rate with given demand is considered in respectively to avoid shortages [17].

2. The unit production cost is taken as [see for reference: [8] $f(p)=C+\frac{g}{p}+b P$. Here, $C$ is the unit cost of raw material, $g$ represents the per unit cost component that is reduced as the production rate increases, and $b P$ is the unit cost component that increases in the production rate (e.g., tools costs) $[48,49]$.

3. The agri-product processing firm outsources few operations due to limited resources. The imperfect products are produced, for which reworking is done and inspection cost is incurred. The rejected products are disposed and recycled.

4. The model is applicable for non-perishable crop because it considers only a sugar processing firm with outsourcing operation.

5. The processing firm consisting the combination of labor and equipment/machines to process the agri-product.

6. Management of imperfection and carbon emission is considered to make the Agri-SCM a cleaner and eco-effective model.

\subsubsection{Notation}

The decision variables and the parameters used in the proposed mathematical modeling are denoted by the notations enlisted comprehensively in Appendix A.

\subsection{Model Formulation}

The inventory diagram of the imperfect agri-food processing firm with vendor/supplier is shown as in Figure 1, where the cycle time of production is given on the x-axis and inventory is given on the $y$-axis. The upper portion is showing the inventory of the agri-product processing firm, while the lower portion is associated with the vendor inventory. The objective of the research is to minimize the total cost of Agri-SCM, and the formulation of the cycle time of the processing firm is prerequisite to calculate the total cost (TC). Cycle time is taken as a decision variable in the production model, which is dependent upon the production rates of processing firm. The production rate of the processing firm, i.e., $P_{j a}$ and $P_{j c}$ for first and final stage is relying on the production rate of the machines $\left(\varepsilon_{j a}\right.$ and $\left.\varepsilon_{j c}\right)$. In order to meet the customer demand and no shortages in the processing firm, the production rates are considered as a variable (i.e., $\varepsilon_{j a}^{*}$ and $\varepsilon_{j c}^{*}$ ) to take an advantage of flexible production, where, $\varepsilon_{j a}^{*} \in\left[\varepsilon_{j a-m_{i n}}^{*} \varepsilon_{j a-\max }^{*}\right]$ 
and $\varepsilon_{j a}^{*} \in\left[\varepsilon_{j c-\min }^{*}, \varepsilon_{j c-\max }^{*}\right]$. The total cost of production is the sum of Agri-processing firm and vendor cost as given in Equation (1) and their formulations are further represented as following.

$$
\text { Total cost of production }=\text { Agri-processing cost }+ \text { Vendor cost }
$$

\subsubsection{Agri-Processing Cost}

The total cost associated with the manufacturer include the cost related to the first stage and final stage of the processing firm, where the basic cost includes setup, production, labor, holding, carbon emission, and stress, as expressed in Equation (2).

$$
\begin{gathered}
\text { Total cost of agri-processing }=\text { Setup cost }+ \text { processing cost }+ \text { Labor cost } \\
+ \text { Holding cost }+ \text { Carbon emissions cost }
\end{gathered}
$$

The breakup of the agri-processing cost is necessary to understand each cost clearly. That is the reason all the costs are described mathematically and theoretically in Equations (3)-(10) as follows.

\subsubsection{Setup Cost}

The incurred cost is subject to the initial cost required to operate the production setup. Generally, it may contain setup cost, substitution, and tool setting cost. Further, this is fixed nature cost, independent of quantities, though time dependent. The expression is given in Equation (3).

$$
S C=\sum_{j=1}^{J} A_{j}
$$

\subsubsection{Production Cost}

Explicitly, cost incurred in the processing, which is largely dependent on quantity and variable in nature. The cost is accumulation of all costs utilized on resources that are required to manufacture a product. It contains the processing and machining cost, utilities needed for machines, and labor cost. Further, it is linked with the manufacturing processes of initial stage manufacturing. and are the production rates of the initial stage processing plant and machines respectively. Lastly, the production cost is the summation of all the costs linked with the raw materials, production, and tool-die cost [50]. The expression is given as in Equation (4).

$$
M C=\sum_{j=1}^{J}\left(C_{r m}+T D_{m a j} P_{j a}+\frac{g_{m a j}}{P_{j a}}\right) P_{j a} t_{1 j}+\left(T D_{m c j} P_{j c}+\frac{g_{m c j}}{P_{j c}}\right) Q_{j c}
$$

\subsubsection{Holding Cost}

Holding cost is the basic cost need to understand the basic production model, which is variable and dependent upon the variable inventory at any instant of time. This is the carrying cost of holding inventory. Holding cost depends on production of semi-finished and finished goods used as stock. It is incurred on production and crashing quantities in the proposed model and includes costs such as wedges, warehouse rent, and insurance. It also depends on the holding time of the product in inventory. The holding cost will be applied on the inventory supported by manufacturing firm, outsourcing operations. The average inventory is calculated as the ratio of the sum of inventories in the form of area under the curve to the cycle time of the production, which is expressed as in Equation (7). The cycle time and inventory levels of the processing firm are calculated by a step-by-step procedure gives in Appendix B.

$$
\text { TotalInventory }=\text { Area }_{123}+\text { Area }_{10,11,12}+\text { Area }_{11,12,13}
$$




$$
\begin{gathered}
=\frac{Q_{j}^{2}}{2 P_{j a}}+\frac{\left(Q_{j}-u\right)^{2}}{2 P_{j c}}\left(1-\frac{D_{j}}{P_{j c}}\right)+\frac{\left(Q_{j}+u\right)^{2}}{2 D_{j}}\left(1-\frac{D_{j}}{P_{j c}}\right)^{2} \\
H C_{m j}=\sum_{j=1}^{J} h_{m j}\left[\frac{Q_{j}^{2}}{2 P_{j a}}+\frac{\left(Q_{j}-u\right)^{2}}{2 P_{j c}}\left(1-\frac{D_{j}}{P_{j c}}\right)+\frac{\left(Q_{j}+u\right)^{2}}{2 D_{j}}\left(1-\frac{D_{j}}{P_{j c}}\right)^{2}\right] .
\end{gathered}
$$

\subsubsection{Carbon Emission Costs}

The model optimized the carbon emission cost as a function of production rate to develop an eco-friendly and eco-effective agri-product SCM. The carbon emission in the agri-processing firm depends upon the source of energy consumed by the equipment/machines. The cost of carbon is incurred by the state government to support the global warming issue. The cost of carbon emission is generated during the life cycle production, which is given as in Equation (9), where $A$ is the emissions function parameter (ton.year/unit), $B$ is the emissions function parameter (ton year/unit), and $C$ is the emissions function parameter (ton/unit) [51].

$$
\begin{gathered}
\text { Carbon emission cost }\left(C E C_{j}\right)=\text { Costofcarbonemissioninmanu facturing }(C E M) \\
=\sum_{j=1}^{J} \gamma_{2}\left[\left(A P_{j a}^{2}-B P_{j a}+C\right) P_{j a} t_{1 j}+\left(A P_{j c}^{2}-B P_{j c}+C\right) Q_{j c}\right]
\end{gathered}
$$

\subsubsection{Labor Cost}

The cost is associated with the utilization of the workforce in the agri-SCM. The wages paid to the workers on the basis of the level of the skilled. Here, the cost is incurred to reflect the importance of the unskilled workers to understand the importance of the human factor in the processing firm. The labor cost is calculated on the basis of the machines required in the agri-product processing firm, which is expressed in Equation (10).

$$
\operatorname{Laborcost}(L C)=\sum_{j=1}^{J} L_{j} W_{j}
$$

The number of machines required and the amount of labor required in the processing firm are given in Equations (11) and (13), where $l_{\mathrm{aj}}$, and $l_{\mathrm{cj}}$ are the labor rate or the number of labors working on each machine.

$$
K_{j}=K_{j a}+K_{j c}
$$

Numberoflabors $=$ Laborrate $\times$ Numberofmachines $\times$ Productiontime

$$
L_{j}=\frac{l_{a j}}{\rho} K_{j a}+\frac{l_{c j}}{\rho} K_{j c}
$$

\subsubsection{Stress and Workers' Efficiency}

The efficiency of the processing firm depends upon the efficiency of the workers to fulfill the customer demand before deadline. The labor-machine coordination in the processing firm is very important for effective and efficient processing firm. The relationship between the average worker's stress and efficiency is expressed as given in Equation (15), where $m$ is scale factor, $\rho_{0}$ is the workers' efficiency affected by stress, and $\rho_{1}$ is the efficiency due to the effect of another factor. Therefore, the total efficiency of the worker will be $\rho[52,53]$.

$$
\rho_{0}=e^{-s / m},
$$




$$
\rho=\rho_{1} \rho_{0}
$$

\subsubsection{Stress Level and Defective Rate}

The relationship is developed between the defective rate and averages stress among worker, where the defective rate is considered as a function of stress having a significant impact on the processing firm. The increasing rate of average stress among workers increases the defective rate. That is the reason, the expression for defective is the sum of initial and variable defective rate as expressed in the Equation (16), where variable defective rate is a function of stress among workers, $\alpha_{0}$ is the initial defective rate, $\tau$ and, $\epsilon$ are the scaling factors, and $s$ is average stress among worker [53]. The analysis of workers' stress on the production system has already been analysed by the research work of Omair et al. [53]. Therefore, the formulation has been incorporated in this study. However, the analysis of workplace stress on the production system is not highlighted.

$$
\alpha_{j}=\alpha_{0}+\tau(s)^{\epsilon} .
$$

Now, the mathematical form of the total cost of the agri-processing firm is expressed as in Equation (17).

$$
\begin{aligned}
T C_{a j}=\sum_{j=1}^{J}[ & A_{j}+\left(C_{r m}+T D_{m a j} P_{j a}+\frac{g_{m a j}}{P_{j a}}\right) P_{j a} t_{1 j}+\left(T D_{m c j} P_{j c}+\frac{g_{m c j}}{P_{j c}}\right) Q_{j c}+L_{j} W_{j} \\
& +h_{m j}\left[\frac{Q_{j}^{2}}{2 P_{j a}}+\frac{\left(Q_{j}-u\right)^{2}}{2 P_{j c}}\left(1-\frac{D_{j}}{P_{j c}}\right)+\frac{\left(Q_{j}+u\right)^{2}}{2 D_{j}}\left(1-\frac{D_{j}}{P_{j c}}\right)^{2}\right] \\
+ & \left.\gamma_{2}\left[\left(A P_{j a}^{2}-B P_{j a}+C\right) P_{j a} t_{1 j}+\left(A P_{j c}^{2}-B P_{j c}+C\right) Q_{j c}\right]+s S C_{j}\right] .
\end{aligned}
$$

The costs related to the manufacturer in the first and final stages of production are calculated, and the costs associated with the vendor are given in the next section.

\subsection{Vendor Cost}

The semi-finished agri-products are delivered to the vendor for processing few operations. The cost of vendor is the sum of the costs associated with the production, holding, inspection, and recycling of the processes is given in Equation (18). These costs are expressed in the Equations (19)-(24).

$$
\begin{gathered}
\text { Vendor cost }=\text { Production cost }+ \text { Holding cost }+ \text { Inspection cost }+ \text { Reworking cost } \\
+ \text { Scrap recycle cost }+ \text { Buffer cost }
\end{gathered}
$$

\subsubsection{Production Cost of Outsourcing}

The expression for production cost is utilized from the research work done by [50] except the cost of raw material, because of receiving the semi-finished products from the manufacturer. The expression is given in Equation (19).

$$
M C O=\sum_{j=1}^{J}\left[\left(T D_{o j} P_{j b}\left(1-\alpha_{j}\right)+\frac{g_{o j}}{P_{j b}\left(1-\alpha_{j}\right)}\right) P_{j b}\left(1-\alpha_{j}\right) t_{2 j}\right] .
$$

\subsubsection{Holding Cost of Vendor}

The holding cost of outsourcing operations is obtained by the sum of inventories calculated from Appendix B. The expression for calculating the total cost of production is expressed in Equation (22).

$$
\text { Total Inventory }=\text { Area } 456+\text { Area5678 }+ \text { Area689 }
$$




$$
\begin{gathered}
=\frac{Q_{j}^{2}\left(1-\alpha_{j}\right)}{2 P_{j b}}+\frac{\alpha_{j}\left(1-\alpha_{j}\right) Q_{j}^{2}}{P_{j b}}+\frac{\alpha_{j}^{2} Q_{j}^{2}\left(1-\alpha_{j} \beta_{j}\right)}{2 P_{j b}}, \\
H C=\sum_{j=1}^{J}\left[h_{o j}\left[\frac{Q_{j}^{2}\left(1-\alpha_{j}\right)}{2 P_{j b}}+\frac{\alpha_{j}\left(1-\alpha_{j}\right) Q_{j}^{2}}{P_{j b}}+\frac{\alpha_{j}^{2} Q_{j}^{2}\left(1-\alpha_{j} \beta_{j}\right)}{2 P_{j b}}\right]\right] .
\end{gathered}
$$

\subsubsection{Inspection Cost}

Inspection of the agri-product is carried out by the vendor, where the products are checked according to the quality control dimensions. The parts are categorized into good and rejected. The total inspection cost of the production is the sum of the fixed and variable inspection cost in the processing, as expressed in Equation (23).

$$
I C_{j}=\sum_{j=1}^{J}\left[\theta_{j}+\psi_{j a} P_{j a} t_{1 j}+\psi_{j b} P_{j b} t_{2 j}\right]
$$

\subsubsection{Recycling Cost/Disposal Cost}

Recycling cost is considered in the agri-processing firm. It is not concerned with the recycling of the agri-product after deteriorated but it is the cost incurred on rejected/defective or imperfect agri-product. The customer/user is not the part of the proposed agricultural supply chain management (Agri-SCM) that is the reason, the perishability factor is not considered. Here, recycling cost is the cost incurred on disposing the imperfect/defective not due to deterioration or perishability factor. These products are bio-waste and further utilized into other byproducts, i.e., fertilizers, bio-fuel, feeds, etc., in the processing expressed as in the equation given below.

$$
R C_{j}=\gamma_{1} P_{j b} t_{2 j} \alpha_{j} \beta_{j}
$$

The mathematical expression to sum all the costs equations is represented as given in Equation (24).

$$
\begin{gathered}
T C_{v j}=\sum_{j=1}^{J}\left[\left(T D_{o j} P_{j b}\left(1-\alpha_{j}\right)+\frac{g_{o j}}{P_{j b}\left(1-\alpha_{j}\right)}\right) P_{j b}\left(1-\alpha_{j}\right) t_{2 j}+\frac{Q_{j}^{2}\left(1-\alpha_{j}\right)}{2 P_{j b}}+\frac{\alpha_{j}\left(1-\alpha_{j}\right) Q_{j}^{2}}{P_{j b}}\right. \\
\left.+\frac{\alpha_{j}^{2} Q_{j}^{2}\left(1-\alpha_{j} \beta_{j}\right)}{2 P_{j b}}+\theta_{j}+\psi_{j a} P_{j a} t_{1 j}+\psi_{j b} P_{j b} t_{2 j}+\gamma_{1} P_{j b} t_{2 j} \alpha_{j} \beta_{j}\right]
\end{gathered}
$$

The production system of agri-product processing firm is analyzed by the formulation of mathematical model. The mathematically model is based on the cycle time of production. The objective of the proposed model is to minimize the total $\operatorname{cost}\left(T C_{s j}\right)$ of processing firm. The total cost per cycle is given in Equation (26).

$$
\begin{gathered}
\text { Totalcost }=\text { Agri-processingcost }+M R(\text { Vendorcost }) \\
T C_{j}=\sum_{j=1}^{J} \frac{1}{T_{j}}\left[A_{j}+\left(C_{r m}+T D_{m a j} P_{j a}+\frac{g_{m a j}}{P_{j a}}\right) P_{j a} t_{1 j}+\left(T D_{m c j} P_{j c}+\frac{g_{m c j}}{P_{j c}}\right) Q_{j c}+L_{j} W_{j}\right. \\
+h_{m j}\left[\frac{Q_{j}^{2}}{2 P_{j a}}+\frac{\left(D_{j} T_{j}\right)^{2}}{2 P_{j c}}\left(1-\frac{D_{j}}{P_{j c}}\right)+\frac{\left(Q_{j}+u\right)^{2}}{2 D_{j}}\left(1-\frac{D_{j}}{P_{j c}}\right)^{2}\right]+\gamma_{2}\left[\left(A P_{j a}^{2}-B P_{j a}+C\right) P_{j a} t_{1 j}\right. \\
\left.+\left(A P_{j c}^{2}-B P_{j c}+C\right) Q_{j c}\right]+s \cdot S C_{j}+M R\left[\left(T D_{o j} P_{j b}\left(1-\alpha_{j}\right)+\frac{g_{o j}}{P_{j b}\left(1-\alpha_{j}\right)}\right) P_{j b}\left(1-\alpha_{j}\right) t_{2 j}\right. \\
+\frac{Q_{j}^{2}\left(1-\alpha_{j}\right)}{2 P_{j b}}+\frac{\alpha_{j}\left(1-\alpha_{j}\right) Q_{j}^{2}}{P_{j b}}+\frac{\alpha_{j}^{2} Q_{j}^{2}\left(1-\alpha_{j} \beta_{j}\right)}{2 P_{j b}}+\theta_{j}+\psi_{j a} P_{j a} t_{1 j}+\psi_{j b} P_{j b} t_{2 j} \\
\left.\left.+R_{j} \alpha_{j} Q_{j}\left(1-\alpha_{j} \beta_{j}\right)+\gamma_{1} P_{j b} t_{2 j} \alpha_{j} \beta_{j}\right]\right]
\end{gathered}
$$


where,

$$
\begin{gathered}
L_{j}=L_{j a}+L_{j c} \\
Q_{j}=\frac{T_{j} D_{j}(\Omega)}{1-\alpha_{j}^{2} \beta_{j}} \\
t_{1 j}=\frac{T_{j} D_{j}}{K_{j a} \varepsilon_{j a}\left(1-\alpha_{j}^{2} \beta_{j}\right)} \\
t_{2 j}=\frac{T_{j} D_{j}}{P_{j b}\left(1-\alpha_{j}^{2} \beta_{j}\right)} \\
t_{4 j}=\frac{T_{j} D_{j}}{K_{j c} \varepsilon_{j c}} \\
t_{5 j}=\left(\frac{T_{j} D_{j}}{1-\alpha_{j}^{2} \beta_{j}}-u\right)\left(\frac{K_{j c} \varepsilon_{j c}-D_{j}}{D_{j} K_{j c} \varepsilon_{j c}}\right)
\end{gathered}
$$

The SCM mathematical model is non-linear by minimizing total cost of SCM, where the decision variables are $\left(T_{j}, L_{j a}, L_{j c}, K_{j a}, K_{j c}, P_{j a}\right.$, and $\left.P_{j c}\right)$.

\subsection{Solution Algorithm}

The variability in the proposed Agri-SCM model make the model non-linear in nature. The decision variables considered are relying on the decisions of the production planning. Analytically, the proposed model is optimized with the help of improved methodology called algebraic function, which is based on quadratic equation. There are four decision variables, i.e., cycle time $\left(T_{j}\right)$, machines $\left(K_{j a}, K_{j c}\right)$, production rate $\left(\varepsilon_{j a}, \varepsilon_{j c}\right)$, and labors $\left(L_{j a}, L_{j c}\right)$ to optimize the non-linear imperfect production model. The algebraic method consists of a positive expression type, and can be rewritten as:

$$
\begin{gathered}
f(x)=a_{1} x+a_{2} / x+a_{3}=\frac{a_{1}}{x}\left(x^{2}+a_{2} / a_{1}-2 x \sqrt{a_{2} / a_{1}}+2 x \sqrt{a_{2} / a_{1}}\right)+a_{3} \\
f(x)=\frac{a_{1}}{x}\left(x^{2}+a_{2} / a_{1}-2 x \sqrt{a_{2} / a_{1}}\right)+2 a_{1} \sqrt{a_{2} / a_{1}}+a_{3} \\
f(x)=\frac{a_{1}}{x}\left(x-\sqrt{a_{2} / a_{1}}\right)^{2}+2 \sqrt{a_{2} a_{1}}+a_{3}
\end{gathered}
$$

Since the quadratic expression is non-negative and $a_{1}$ is positive, it is always minimized for $x=\sqrt{a_{2} / a_{1}}$, which reaches the minimum at $f(x)=2 \sqrt{a_{2} / a_{1}}+a_{3}$.

In the first step of solution algorithm, by using algebraic function methodology, the form of decision variable $T_{j}$ can be written as given in Equation (30).

$$
\begin{gathered}
T C_{s j}\left(T_{j}, K_{j a}, K_{j c}, L_{j a}, L_{j c}, \varepsilon_{j a}, \varepsilon_{j c}\right)=\frac{1}{T_{j}}\left[A_{j}+\left(C_{r m}+T D_{m a j} P_{j a}+\frac{g_{m a j}}{P_{j a}}\right) P_{j a} t_{1 j}\right. \\
+\left(T D_{m c j} P_{j c}+\frac{g_{m c j}}{P_{j c}}\right) Q_{j c}+L_{j} W_{j}+h_{m j}\left[\frac{Q_{j}^{2}}{2 P_{j a}}+\frac{\left(D_{j} T_{j}\right)^{2}}{2 P_{j c}}\left(1-\frac{D_{j}}{P_{j c}}\right)+\frac{\left(Q_{j}+u\right)^{2}}{2 D_{j}}\left(1-\frac{D_{j}}{P_{j c}}\right)^{2}\right] \\
+\gamma_{2}\left[\left(A P_{j a}^{2}-B P_{j a}+C\right) P_{j a} t_{1 j}+\left(A P_{j c}^{2}-B P_{j c}+C\right) Q_{j c}\right]+s . S C_{j}+M R\left[\left(T D_{o j} P_{j b}\left(1-\alpha_{j}\right)\right.\right. \\
\left.+\frac{g_{o j}}{P_{j b}\left(1-\alpha_{j}\right)}\right) P_{j b}\left(1-\alpha_{j}\right) t_{2 j}+\frac{Q_{j}^{2}\left(1-\alpha_{j}\right)}{2 P_{j b}}+\frac{\alpha_{j}\left(1-\alpha_{j}\right) Q_{j}^{2}}{P_{j b}}+\frac{\alpha_{j}^{2} Q_{j}^{2}\left(1-\alpha_{j} \beta_{j}\right)}{2 P_{j b}}+\theta_{j} \\
\left.\left.+\psi_{j a} P_{j a} t_{1 j}+\psi_{j b} P_{j b} t_{2 j}+R_{j} \alpha_{j} Q_{j}\left(1-\alpha_{j} \beta_{j}\right)+\gamma_{1} P_{j b} t_{2 j} \alpha_{j} \beta_{j}\right]\right]
\end{gathered}
$$

The Equation (30) can be written as in Equation (31) 


$$
\begin{gathered}
=\frac{1}{T_{j}}\left[A_{j}+s . S C_{j}+\theta_{j}+M R \times T D_{o j} P_{j b}\left(1-\alpha_{j}\right)\right]+T_{j}\left[h _ { m j } \left[\frac{D_{j}^{2}}{2 P_{j a}\left(1-\alpha_{j} \beta_{j}\right)^{2}}\right.\right. \\
\left.+\frac{1}{2 P_{j c}}\left(\frac{D_{j}}{1-\alpha_{j}^{2} \beta_{j}}-\frac{\alpha_{j} \beta_{j} D_{j}}{1-\alpha_{j}^{2} \beta_{j}}\right)^{2}\left(1-\frac{D_{j}}{P_{j c}}\right)+\left(\frac{D_{j}}{1-\alpha_{j}^{2} \beta_{j}}-\frac{\alpha_{j} \beta_{j} D_{j}}{1-\alpha_{j}^{2} \beta_{j}}\right)^{2}\left(1-\frac{D_{j}}{P_{j c}}\right)^{2}\right] \\
\left.+M R\left[\left(\frac{D_{j}}{1-\alpha_{j}^{2} \beta_{j}}\right)^{2} \frac{1-\alpha_{j}}{2 P_{j b}}+\frac{\alpha_{j}\left(1-\alpha_{j}\right)}{P_{j b}}\left(\frac{D_{j}}{1-\alpha_{j}^{2} \beta_{j}}\right)^{2}+\frac{\alpha_{j}^{2}\left(1-\alpha_{j} \beta_{j}\right)}{2 P_{j b}}\left(\frac{D_{j}}{1-\alpha_{j}^{2} \beta_{j}}\right)^{2}\right]\right]
\end{gathered}
$$

Our assumptions are given as in Equations (32) and (33).

$$
\begin{gathered}
A_{1}=\sum_{j=1}^{J}\left[A_{j}+s . S C_{j}+\theta_{j}+M R \times T D_{o j} P_{j b}\left(1-\alpha_{j}\right)\right] \\
A_{2}=\sum_{j=1}^{J}\left[h _ { m j } \left[\frac{D_{j}^{2}}{2 P_{j a}\left(1-\alpha_{j} \beta_{j}\right)^{2}}+\frac{1}{2 P_{j c}}\left(\frac{D_{j}}{1-\alpha_{j}^{2} \beta_{j}}-\frac{\alpha_{j} \beta_{j} D_{j}}{1-\alpha_{j}^{2} \beta_{j}}\right)^{2}\left(1-\frac{D_{j}}{P_{j c}}\right)+\left(\frac{D_{j}}{1-\alpha_{j}^{2} \beta_{j}}-\frac{\alpha_{j} \beta_{j} D_{j}}{1-\alpha_{j}^{2} \beta_{j}}\right)^{2}\right.\right. \\
\left.\left(1-\frac{D_{j}}{P_{j c}}\right)^{2}\right]+M R\left[\left(\frac{D_{j}}{1-\alpha_{j}^{2} \beta_{j}}\right)^{2} \frac{1-\alpha_{j}}{2 P_{j b}}+\frac{\alpha_{j}\left(1-\alpha_{j}\right)}{P_{j b}}\left(\frac{D_{j}}{1-\alpha_{j}^{2} \beta_{j}}\right)^{2}\right. \\
\left.\left.+\frac{\alpha_{j}^{2}\left(1-\alpha_{j} \beta_{j}\right)}{2 P_{j b}}\left(\frac{D_{j}}{1-\alpha_{j}^{2} \beta_{j}}\right)^{2}\right]\right],
\end{gathered}
$$

In the algebraic function approach, the constant term becomes neglected and equal to zero. Therefore, the cost function can be given as in Equation (34).

$$
\begin{gathered}
\mathrm{TC}_{s j}\left(T_{j}^{*}, K_{j a}, K_{j c}, L_{j a}, L_{j c}, \varepsilon_{j a}, \varepsilon_{j c}\right)=\frac{A_{1}}{T_{j}}+A_{2} T_{j} \\
=\left(\sqrt{\frac{A_{1}}{T_{j}}}\right)^{2}+\left(\sqrt{A_{2} T_{j}}\right)^{2}, \\
=\left(\sqrt{\frac{A_{1}}{T_{j}}}-\sqrt{A_{2} T_{j}}\right)^{2}+\sqrt{2 A_{1} A_{2}} .
\end{gathered}
$$

By the algebraic approach, in Equation (36), having the square term as a maximum value, the square will be zero, i.e.,

$$
\begin{gathered}
\left(\sqrt{\frac{A_{1}}{T_{j}}}-\sqrt{A_{2} T_{j}}\right)^{2}=0, \\
\sqrt{\frac{A_{1}}{T_{j}}}-\sqrt{A_{2} T_{j}}=0, \\
\sqrt{\frac{A_{1}}{T_{j}}}=\sqrt{A_{2} T_{j}}, \\
T_{j}^{*}=\sqrt{\frac{A_{1}}{A_{2}}}
\end{gathered}
$$

By putting the value of in Equation (34). The Equation (41) is obtained as.

$$
\mathrm{TC}_{s j}\left(T_{j}^{*}, K_{j a}, K_{j c}, L_{j a}, L_{j c}, \varepsilon_{j a}, \varepsilon_{j c}\right)=\sum_{j=1}^{J} \frac{A_{1}}{T_{j}^{*}}+A_{2} T_{j}^{*} .
$$


In the second step, the production rate of each machine in the first stage $\left(\varepsilon_{j a}\right)$ and final stage $\left(\varepsilon_{j c}\right)$ of the production system are also calculated by using algebraic approach. First of all, to find optimal $\left(\varepsilon_{j c}\right)$, the $T C_{s j}$ can be converted into the form given as in the following equation:

$$
\begin{gathered}
T C_{s j}\left(T_{j}^{*}, K_{j a}, K_{j c}, L_{j a}, L_{j c}, \varepsilon_{j a}, \varepsilon_{j c}\right)=\varepsilon_{j c}\left[T D_{m c} K_{j c} D_{j}-B K_{j c} \gamma_{2} D_{j}\right] \\
+\frac{1}{\varepsilon_{j c}}\left[\frac{g_{m c j} D_{j}}{K_{j c}}+\frac{l_{c j} D_{j} W_{j}}{\rho}+\frac{h_{m j}\left(Q_{j}-u\right)^{2}}{2 K_{j c} T_{j}^{*}}-\frac{\left(Q_{j}+u\right)^{2} h_{m j}}{K_{j c} T_{j}^{*}}\right] \\
+\left[-\frac{h_{m j}}{T_{j}^{*}}\left\{\frac{\left(Q_{j}-u\right)^{2}}{2 K_{j c}} \frac{D_{j}}{\left(\varepsilon_{j c}\right)^{2}}+\frac{\left(Q_{j}+u\right)^{2}}{2 D_{j}} \frac{D_{j}}{\rho K_{j c} \varepsilon_{j c}}\right\}+\gamma_{2} T_{j}^{*} D_{T} A\left(K_{j c} \varepsilon_{j c}\right)^{2}\right] \\
+\left[\gamma_{2} D_{j} \varepsilon_{j a}+\frac{\left(Q_{j}+u\right)^{2}}{2 D_{j} T_{j}^{*}} h_{m j}+\frac{l_{a j} D_{j} W_{j}}{\rho \varepsilon_{j a}\left(1-\alpha_{j}^{2} \beta j\right)}\right] \\
R_{2}=\frac{1}{\varepsilon_{j c}}\left[\frac{g_{m c j} D_{j}}{K_{j c}}+\frac{l_{c j} D_{j} W_{j}}{\rho}+\frac{h_{m j}\left(Q_{j}-u\right)^{2}}{2 K_{j c} T_{j}^{*}}-\frac{\left(Q_{j}+u\right)^{2} h_{m j}}{K_{j c} T_{j}^{*}}\right] \\
R_{3}=\left[-\frac{h_{m j}}{T_{j}^{*}}\left\{\frac{\left(Q_{j}-u\right)^{2}}{2 K_{j c}} \frac{D_{j}}{\left(\varepsilon_{j c}\right)^{2}}+\frac{\left(Q_{j}+u\right)^{2}}{2 D_{j}} \frac{D_{j}}{\rho K_{j c} \varepsilon_{j c}}\right\}+\gamma_{2} T_{j}^{*} D_{j} A\left(K_{j c} \varepsilon_{j c}\right)^{2}\right] \\
R_{4}=\left[\gamma_{2} D_{j} \varepsilon_{j a}+\frac{\left(Q_{j}+u\right)^{2}}{2 D_{j} T_{j}^{*}} h_{m j}+\frac{l_{a j} D_{j} W_{j}}{\rho \varepsilon_{j a}\left(1-\alpha_{j}^{2} \beta j\right)}\right] \\
T C_{s j}\left(T_{j}^{*}, K_{j a}, K_{j c}, L_{j a}, L_{j c}, \varepsilon_{j a}, \varepsilon_{j c}\right)=R_{1} \varepsilon_{j c}+\frac{R_{2}}{\varepsilon_{j c}}+R_{3}+R_{4}
\end{gathered}
$$

$R_{3}$ consists of squared $\varepsilon_{j c}$ and also in the denominator, whereas $R_{4}$ is constant term. Therefore, both are neglected and considered as zero.

$$
\begin{gathered}
T C_{s j}\left(T_{j}^{*}, K_{j a}, K_{j c}, L_{j a}, L_{j c}, \varepsilon_{j a}, \varepsilon_{j c}\right)=\left(\sqrt{R_{1} \varepsilon_{j c}}\right)^{2}+\left({\sqrt{\frac{R_{2}}{\varepsilon_{j c}}}}^{2}\right. \\
=\left(\sqrt{R_{1} \varepsilon_{j c}}-\sqrt{\frac{R_{2}}{\varepsilon_{j c}}}\right)^{2}+2 \sqrt{R_{1} R_{2}} \varepsilon_{j c}
\end{gathered}
$$

By the algebraic approach, Equation (49), having the square term as a maximum value, the squared expression will be zero, i.e.,

$$
\begin{gathered}
\left(\sqrt{R_{1} \varepsilon_{j c}}-\sqrt{\frac{R_{2}}{\varepsilon_{j c}}}\right)=0 \\
\varepsilon_{j c}^{*}=\sqrt{\frac{R_{2}}{R_{1}}}
\end{gathered}
$$

In step 2, the optimal $\varepsilon_{j a}$ is obtained by using algebraic approach, i.e., the $T C_{s j}$ can be given as in Equation (52).

$$
\begin{gathered}
T C_{s j}\left(T_{j}^{*}, K_{j a}, K_{j c}, L_{j a}, L_{j c}, \varepsilon_{j a}, \varepsilon_{j c}^{*}\right)=\varepsilon_{j a}\left[T D_{m a j} K_{j a} D_{j}-\gamma_{2} D_{j} B K_{j a} h_{m j}\right] \\
+\frac{1}{\varepsilon_{j a}}\left[\frac{g_{m a j} D_{j}}{K_{j a}}+\frac{l_{a j} D_{j} W_{j}}{\rho\left(1-\left(\alpha_{j}\right)^{2} \beta_{j}\right)}+\frac{h_{m j}\left(Q_{j}\right)^{2}}{2 T_{j}^{*} K_{j a}}\right] \\
+\left[\frac{l_{c j} D_{j} W_{j}}{\rho \varepsilon_{j c}^{*}}+\gamma_{2} h_{m j} A\left(K_{j a} \varepsilon_{j a}\right)^{2} D_{j}+\gamma_{2} \varepsilon_{j c}^{*} D_{j} h_{m j}\right]
\end{gathered}
$$


where we can assume that

$$
\begin{gathered}
R_{5}=\varepsilon_{j a}\left[T D_{m a j} K_{j a} D_{j}-\gamma_{2} D_{j} B K_{j a} h_{m j}\right] \\
R_{6}=\frac{1}{\varepsilon_{j a}}\left[\frac{g_{m a j} D_{j}}{K_{j a}}+\frac{l_{a j} D_{j} W_{j}}{\rho\left(1-\left(\alpha_{j}\right)^{2} \beta_{j}\right)}+\frac{h_{m j}\left(Q_{j}\right)^{2}}{2 T_{j}^{*} K_{j a}}\right] \\
R_{7}=\left[\frac{l_{c j} D_{j} W_{j}}{\rho \varepsilon_{j c}^{*}}+\gamma_{2} h_{m j} A\left(K_{j a} \varepsilon_{j a}\right)^{2} D_{j}+\gamma_{2} \varepsilon_{j c}^{*} D_{j} h_{m j}\right]
\end{gathered}
$$

Therefore, Equation (56) can be written as

$$
\begin{gathered}
T C_{s j}\left(T_{j}^{*}, K_{j a}, K_{j c}, L_{j a}, L_{j c}, \varepsilon_{j a}, \varepsilon_{j c}^{*}\right)=R_{5} \varepsilon_{j a}+\frac{R_{6}}{\varepsilon_{j a}}+R_{7} \\
=\left(\sqrt{R_{5} \varepsilon_{j a}}\right)^{2}+\left({\sqrt{\frac{R_{6}}{\varepsilon_{j a}}}}^{2}+R_{7}\right.
\end{gathered}
$$

where $R_{7}$ is squared $\varepsilon_{j a}$, which can be neglected and considered as zero.

$$
\begin{gathered}
T C_{s j}\left(T_{j}^{*}, K_{j a}, K_{j c}, L_{j a}, L_{j c}, \varepsilon_{j a}, \varepsilon_{j c}^{*}\right)=\left(\sqrt{R_{5} \varepsilon_{j a}}-\sqrt{\frac{R_{6}}{\varepsilon_{j a}}}\right)^{2}+2 \sqrt{R_{5} R_{6}} \\
=\left(\sqrt{R_{5} \varepsilon_{j a}}-\sqrt{\frac{R_{6}}{\varepsilon_{j a}}}\right)+2 \sqrt{R_{5} R_{6}}
\end{gathered}
$$

The square term has a maximum value, if the squared expression will be zero, i.e.,

$$
\varepsilon_{j a}^{*}=\sqrt{\frac{R_{6}}{R_{5}}}
$$

In the third step, the other decision variables of the production system i.e., $K_{j c}, L_{j a}$, and $L_{j c}$, which are discrete and can be calculated indirectly. Therefore, the total cost from Equation (30) will be given as in Equation (61):

$$
\begin{aligned}
& T C_{s j}\left(T_{j}^{*}, K j a^{*}, K j c^{*}, L j a^{*}, L j c^{*}, \varepsilon_{j a}^{*}, \varepsilon_{j c}^{*}\right)=\frac{1}{T_{j}^{*}}\left[A_{j}+\left(C_{r m}+T D_{m a j}\left(K_{j a}^{*} \varepsilon_{j a}^{*}\right)\right.\right. \\
& \left.+\frac{g_{m a j}}{\left(K_{j a}^{*} \varepsilon_{j a}^{*}\right)}\right)\left(K_{j a}^{*} \varepsilon_{j a}^{*}\right)\left(\frac{T_{j}^{*} D_{j}}{K_{j a}^{*} \varepsilon_{j a}^{*}\left(1-\alpha_{j}^{2} \beta_{j}\right)}\right)+\left(T D_{m c j}\left(K_{j c}^{*} c_{j c}^{*}\right)+\frac{g_{m c j}}{\left(K_{j c}^{*} \varepsilon_{j c}^{*}\right)}\right)\left(K_{j c}^{*} c_{j c}^{*}\right)\left(\frac{T_{j}^{*} D_{j}}{K_{j c}^{*} \varepsilon_{j c}^{*}}\right)+L_{j}^{*} W_{j} \\
& +h_{m j}\left[\frac{\left(\frac{T_{j}^{*} D_{j}}{1-\alpha_{j}^{2} \beta_{j}}\right)^{2}}{\left(2 K_{j a}^{*} \varepsilon_{j a}^{*}\right)}+\frac{\left(D_{j} T_{j}^{*}\right)^{2}}{\left(2 K_{j c}^{*} \varepsilon_{j c}^{*}\right)}\left(1-\frac{D_{j}}{\left(K_{j c}^{*} \varepsilon_{j c}^{*}\right)}\right)+\frac{\left(D_{j} T_{j}^{*}\right)^{2}}{2 D_{j}}\left(1-\frac{D_{j}}{\left(K_{j c}^{*} \varepsilon_{j c}^{*}\right)}\right)^{2}\right] \\
& +\gamma_{2}\left[\left(A\left(K_{j a}^{*} \varepsilon_{j a}^{*}\right)^{2}-B\left(K_{j a}^{*} \varepsilon_{j a}^{*}\right)+C\right)\left(K_{j a}^{*} \varepsilon_{j a}^{*}\right)\left(\frac{T_{j}^{*} D_{j}}{K_{j a}^{*} \varepsilon_{j a}^{*}\left(1-\alpha_{j}^{2} \beta_{j}\right)}\right)+\left(A\left(K_{j c}^{*} \varepsilon_{j c}^{*}\right)^{2}-B\left(K_{j c}^{*} \varepsilon_{j c}^{*}\right)\right.\right. \\
& \left.+C)\left(K_{j c}^{*} \varepsilon_{j c}^{*}\right)\left(\frac{T_{j}^{*} D_{j}}{K_{j c}^{*} \varepsilon_{j c}^{*}}\right)\right]+s . S C_{j}+M R\left[\left(T D_{o j} P_{j b}\left(1-\alpha_{j}\right)+\frac{g_{o j}}{P_{j b}\left(1-\alpha_{j}\right)}\right) P_{j b}\left(1-\alpha_{j}\right)\left(\frac{T_{j}^{*} D_{j}}{P_{j b}\left(1-\alpha_{j}^{2} \beta_{j}\right)}\right)\right. \\
& +\frac{\left(\frac{T_{j}^{*} D_{j}}{1-\alpha_{j}^{2} \beta_{j}}\right)^{2}\left(1-\alpha_{j}\right)}{2 P_{j b}}+\frac{\alpha_{j}\left(1-\alpha_{j}\right)\left(\frac{T_{j}^{*} D_{j}}{1-\alpha_{j}^{2} \beta_{j}}\right)^{2}}{P_{j b}}+\frac{\alpha_{j}^{2}\left(\frac{T_{j}^{*} D_{j}}{1-\alpha_{j}^{2} \beta_{j}}\right)^{2}\left(1-\alpha_{j} \beta_{j}\right)}{2 P_{j b}}+\theta_{j} \\
& +\psi_{j a}\left(K_{j a}^{*} \varepsilon_{j a}^{*}\right)\left(\frac{T_{j}^{*} D_{j}}{K_{j a}^{*} \varepsilon_{j a}^{*}\left(1-\alpha_{j}^{2} \beta_{j}\right)}\right)+\psi_{j b} P_{j b}\left(\frac{T_{j}^{*} D_{j}}{P_{j b}\left(1-\alpha_{j}^{2} \beta_{j}\right)}\right)+R_{j} \alpha_{j}\left(\frac{T_{j}^{*} D_{j}}{1-\alpha_{j}^{2} \beta_{j}}\right)\left(1-\alpha_{j} \beta_{j}\right) \\
& \left.+\gamma_{1} P_{j b}\left(\frac{T_{j}^{*} D_{j}}{P_{j b}\left(1-\alpha_{j}^{2} \beta_{j}\right)}\right) \alpha_{j} \beta_{j}\right]
\end{aligned}
$$


where,

$$
\begin{gathered}
L_{j}=L_{j a}^{*}+L_{j c^{\prime}}^{*} \\
L_{j a}^{*}=\frac{l_{a j} K_{j}^{*}}{\rho},
\end{gathered}
$$

\subsection{Numerical Experiment}

The pragmatic application of the proposed Agri-SCM n model is performed by considering a sugar processing firm with vendor. The local industry is processing sugarcane as a raw material and converting it into sugar. There are various categories of the sugar obtained from the raw material depending on the quality and grades. In our case, we considered three grades of sugar, i.e., A, B, and $C$, respectively. The constraints of budget and resources compelled the sugar processing firm to outsource few processes of the sugar to vendors for a successful supply chain management. To avoid shortages, the managers are required to keep the production rate as a controllable to fix as per demand. The production rate of the sugar processing firm is linked with the integrated production rate of man and machine. The vendor operations are influencing the production rate of the system, which is kept constant. Therefore, it is limited to set the production rate of the operations before delivering the products to the vendor, and this should be greater than the rate of outsourcing operation. Furthermore, the rate of production operations performed after the outsourcing operation must be greater than the outsourcing rate. The numerical experiment of the research study is based on argir-SCM including sugar processing firm and vendor. The data utilized to perform the experiment is taken from the local industry of sugar processing SCM. The processing-based data for each agri-product are given in Table 2, which consists of tool-die, production, holding, and production rate, which is taken from the research work of [50]. On the basis of the capacity of the machines inside processing firm, the variable production rate, $\left[\varepsilon_{a j-\min }, \varepsilon_{a j-\max }\right]$ is considered as $[(120,130,140),(150,160,170)]$ for the machine to process each agri-product at the first stage where $\left[\varepsilon_{c j-\min }, \varepsilon_{c j-\max }\right]$ is considered as $[(110,115,125)$, $(130,140,150)]$ to process each sugar grade processing in finishing stage of the processing.

\begin{tabular}{|c|c|c|c|c|c|}
\hline Product Type & $\begin{array}{l}\text { Tool-Die Cost } \\
\text { 1st Stage } \\
\text { (\$/Machine) }\end{array}$ & $\begin{array}{l}\text { Tool-Die Cost } \\
\text { Finishing } \\
\text { (\$/Machine) }\end{array}$ & $\begin{array}{c}\text { Fixed } \\
\text { Production } \\
\text { Cost (\$/ton) }\end{array}$ & $\begin{array}{c}\text { Fixed } \\
\text { Production } \\
\text { Cost (\$/ton) }\end{array}$ & $\begin{array}{c}\text { Holding } \\
\text { (\$/ton/Year) }\end{array}$ \\
\hline Sugar (A) & 0.012 & 0.09 & 650 & 550 & 1.1 \\
\hline Sugar (B) & 0.012 & 0.085 & 660 & 560 & 1.21 \\
\hline Sugar (C) & 0.013 & 0.095 & 665 & 560 & 1.25 \\
\hline Product Type & Setup (\$/Year) & $\begin{array}{c}\text { Raw Material } \\
\text { Cost (\$/ton) }\end{array}$ & $\begin{array}{c}\text { Production } \\
\text { Rate } \\
\text { (tons/Machine) }\end{array}$ & $\begin{array}{c}\text { Labor } \\
\text { (\$/Labor-Year) }\end{array}$ & $\begin{array}{c}\text { Demand } \\
\text { (tons/Year) }\end{array}$ \\
\hline Sugar (A) & 8 & 20 & 150 & 1000 & 900 \\
\hline Sugar (B) & 8.8 & 23 & 160 & 1000 & 800 \\
\hline Sugar (C) & 9.3 & 25 & 170 & 1000 & 800 \\
\hline
\end{tabular}

Table 2. Agri-processing firm data for processing various sugar grades from sugarcane.

All the data related to the imperfect production are given in Table 3, which cover inspection and recycling. Since the imperfect production is the part of normal production, this model considered few vendor operations. The inspection station is located after outsourcing to check the quality of each agri-product, and sorted the checked parts into good and rejected parts. The inspection cost is categorized as fixed including initial investment and variable cost depending upon the production quantity. The recycling cost includes the operations to recycle the rejected agri-products into other useful product. These costs have a significant impact on the total cost of processing. 
Table 3. Vendor data to process various grades of sugar.

\begin{tabular}{cccc}
\hline Product Type & Tool-Die Cost (\$/Machine) & Fixed Production Cost (\$/tons) & Holding (\$/tons/Year) \\
\hline Sugar (A) & 0.011 & 670 & 1.12 \\
Sugar (B) & 0.012 & 670 & 1.23 \\
Sugar (C) & 0.013 & 675 & 1.28 \\
\hline Product Type & Fixed Inspection (\$/Year) & Variable Inspection (\$/Unit) & Disposal (\$/Unit/Year) \\
\hline Sugar (A) & 5 & 0.12 & 0.83 \\
Sugar (B) & 5.5 & 0.22 & 0.83 \\
Sugar (C) & 6 & 0.28 & 0.83 \\
\hline
\end{tabular}

\section{Results}

\subsection{Numerical Results}

The objective is to make the production plane, where the number of workstations, workers, and production time cycle are required. The production rate of the system is depending upon the production rate of machines, which is kept in such a way that there are no shortages in the system. The systems of equations generated from the proposed model consisting non-linear equations. There are numerous techniques used to find the optimal solution of non-linear models e.g., interior point optimization (IPO), particle swarm optimization (PSO), pattern search (PS), genetic algorithm (GA), min-max optimization (MMO) etc. Analytically, the methodology is proceeded to search the optimal and global solutions. The proposed model is solved with global optimal result and solution as given in Table 4 . The total minimum cost of production is obtained as $\$ 478,491$, which is optimal and better as compared to PSO, PS, and GA as evidence. The possible optimal production plan for the manufacturing of parts $\mathrm{A}, \mathrm{B}$, and $\mathrm{C}$ as a solution consider the production cycle time in days $(5.4,5.76,5.76)$, machine $(9,8,7)$ at the first stage, and $(7,6,6)$ at the final stage of sugar processing, respectively. The number of labors as an indirect decision variable are calculated as $(32,29,25)$ and $(17,15,15)$ for first and final stage of production.

A special case is considered to solve the proposed research model by taking constant production rate of the sugar processing firm. This analysis is important to understand the importance of the controllable production rate by comparing the results. The main objective is to minimize the total cost of production. The proposed research model is solved by using the solution algorithm developed by considering constant production rates of the machines located at first stage and final stage of the production system, i.e., $\varepsilon_{j a}=(140,150,160)$ and $\varepsilon_{j c}=(120,130,140)$. The comparative results on the basis of the $T C_{s j}$ is represented in Table 5 and Figure 2 to show the evaluation of the controllable production rate. It is found that the total cost of production in case of variable production rate is optimal as compared to the special case by taking constant production rate. The total cost of processing is minimum in case of variable production rate i.e., $\$ 478,491$ as compared to special case. In addition, the machines required for the production of products at constant production rate required more machines to fulfill the demand. This result provides an important justification for the transformation of the proposed model into a traditional system, considering a constant production rate for the production system.

Theoretically, the study is a proactive approach for the decision-makers to take advantage of the controllable production rate to avoid excess production of agri-product against fluctuating demand with the minimum optimal cost of Agri-SCM. The solution of the research is provided by incorporating a controllable production rate for flexible manufacturing, inventory level control, optimal carbon emission, and best resource utilization to cope with the fluctuating demand. The research is effective for agricultural businesses to understand the role of controllable production rate for cleaner production. 
Table 4. The optimal result of the production model with solution for the processing of sugar.

\begin{tabular}{cccccc}
\hline $\begin{array}{c}\text { Decision } \\
\text { Variable }\end{array}$ & $\begin{array}{c}\text { Algebraic Approach } \\
\text { (Constant } \\
\text { Production Rate) }\end{array}$ & $\begin{array}{c}\text { Algebraic Approach } \\
\text { (Variable } \\
\text { Production Rate) }\end{array}$ & $\begin{array}{c}\text { Particle } \\
\text { Swarm }\end{array}$ & $\begin{array}{c}\text { Pattern } \\
\text { Search }\end{array}$ & $\begin{array}{c}\text { Genetic } \\
\text { Algorithm }\end{array}$ \\
\hline$T_{1}($ year) & 0.015 & 0.015 & 0.016 & 0.016 & 0.0163 \\
$T_{2}$ (year) & 0.016 & 0.016 & 0.016 & 0.04 & 0.0080 \\
$T_{3}$ (year) & 0.017 & 0.016 & 0.016 & 0.016 & 0.0166 \\
$K_{j a 1}$ (machines) & 10 & 9 & 9 & 9 & 9 \\
$K_{j a 2}$ (machines) & 8 & 8 & 8 & 8 & 8 \\
$K_{j a 3}$ (machines) & 8 & 7 & 7 & 7 & 7 \\
$K_{j c 1}$ (machines) & 8 & 7 & 7 & 7 & 7 \\
$K_{j c 2}$ (machines) & 7 & 6 & 6 & 6 & 74 \\
$K_{j c 3}$ (machines) & 6 & 6 & 6 & 6 & 6 \\
$T_{j s}(\$)$ & 513,890 & 478,491 & $479,045.1$ & $479,500.2$ & $607,138.3$ \\
\hline
\end{tabular}

Table 5. Sensitivity analysis of the SCM with respect to key parameters.

\begin{tabular}{|c|c|c|c|c|}
\hline Parameters & $\begin{array}{l}\text { Original } \\
\text { Value }\end{array}$ & $\begin{array}{l}\% \text { Change } \\
\text { in Value }\end{array}$ & $\begin{array}{l}\text { New } \\
\text { Value }\end{array}$ & $\begin{array}{c}\% \text { Effect on } \\
T C_{j s}\end{array}$ \\
\hline \multirow{4}{*}{$T d_{m j}$} & \multirow{4}{*}{0.01} & -50 & 0.005 & -14.11 \\
\hline & & -25 & 0.01 & -7.16 \\
\hline & & +25 & 0.01 & 7.16 \\
\hline & & +50 & 0.02 & 14.52 \\
\hline \multirow{4}{*}{$g_{j}$} & \multirow{4}{*}{610} & -50 & 305.00 & -0.71 \\
\hline & & -25 & 457.50 & -0.4057 \\
\hline & & +25 & 762.50 & 0.40 \\
\hline & & +50 & 915.00 & 0.71 \\
\hline \multirow{4}{*}{$W_{j}$} & \multirow{4}{*}{1000} & -50 & 500.00 & -21.2 \\
\hline & & -25 & 750.00 & -10.6 \\
\hline & & +25 & 1250.00 & 10.68 \\
\hline & & +50 & 1500.00 & 21.2 \\
\hline \multirow{4}{*}{$C_{j s}$} & \multirow{4}{*}{50} & -50 & 25.00 & -3.14 \\
\hline & & -25 & 37.50 & -1.46 \\
\hline & & +25 & 62.50 & 1.312 \\
\hline & & +50 & 75.00 & 2.513 \\
\hline \multirow{4}{*}{$C_{r m}$} & \multirow{4}{*}{19.5} & -50 & 9.75 & -9.67 \\
\hline & & -25 & 14.63 & -4.83 \\
\hline & & +25 & 24.38 & 4.83 \\
\hline & & +50 & 29.25 & 9.67 \\
\hline \multirow{4}{*}{$H_{j}$} & \multirow{4}{*}{0.5} & -50 & 0.25 & -3.8 \\
\hline & & -25 & 0.38 & -1.92 \\
\hline & & +25 & 0.63 & 1.7 \\
\hline & & +50 & 0.75 & 3.9 \\
\hline \multirow{4}{*}{$A_{j}$} & \multirow{4}{*}{11} & -50 & 5.50 & -0.5 \\
\hline & & -25 & 8.25 & -0.265 \\
\hline & & +25 & 13.75 & 0.27 \\
\hline & & +50 & 16.50 & 0.52 \\
\hline \multirow{4}{*}{$O_{j}$} & \multirow{4}{*}{1.2} & -50 & 0.60 & -4.9 \\
\hline & & -25 & 0.90 & -2.84 \\
\hline & & +25 & 1.50 & 1.663 \\
\hline & & +50 & 1.80 & 4.19 \\
\hline
\end{tabular}




\subsection{Sensitivity Analysis}

The sensitivity analysis of the proposed model is necessary to check the limitation and variation of the system by changing the important factors and parameters. The objective of the proposed model as total cost of agri-processing over short run along is showing a good variation depending upon the change in labor cost, reworking cost, carbon cost, and inspection cost. A sensitivity analysis is necessary to show the effects of varying data on the final objective of the model, i.e., the total profit. Different experiments are also required to test the proposed production model in different situations. There are eight parameters considered as performance indicators for the sensitivity of the proposed model, and the results of the analysis for the SQP technique are given as in Table 5 and also presented graphically in Figure 2.

The sensitivity provides a detailed analysis of the largest effects of the parameters (changes of $-50 \%,-25 \%,+25 \%$ and $50 \%$ ) on the objective function. This analysis is conducted as follows.

1. By changing the tool-die cost $T d_{m j}$ from $-50 \%$ to $+50 \%$, the results exhibit a direct relation, showing respective increases of $+14.11 \%$ and $-14.52 \%$ in the total cost of production system. The original value is at equilibrium, showing symmetric positive and negative effects on the total cost.

2. Similarly, a direct relation is found the production cost $\left(g_{j}\right)$, but the difference is that it had a smaller impact of $\pm 0.71 \%$ on the total profit.

3. From the sensitivity analysis, a large impact of almost $\pm 21 \%$ on the total cost is observed by the variation of labor cost at $\pm 50 \%$.

4. The impact of the manufacturer's raw material cost is also significant on total cost of production i.e., \pm 10 at extreme values.

5. The setup cost $A_{j}$ of the manufacturer shows only small effects of $-0.05 \%$ to $+0.50 \%$ on the cost by changing the rate from $-50 \%$ to $+50 \%$, respectively.

6. The outsourcing cost is found to have a less impact as compared to the production costs resulting in $-4.9 \%$ and $+4.9 \%$ at the extreme points.

7. The holding costs is carrying a nominal impact on $T C_{j s}$, i.e., $-3.8 \%$ and $3.9 \%$ at extreme values. These parameters lie within range of the equilibrium position and are observed to be directly proportional to the objective.

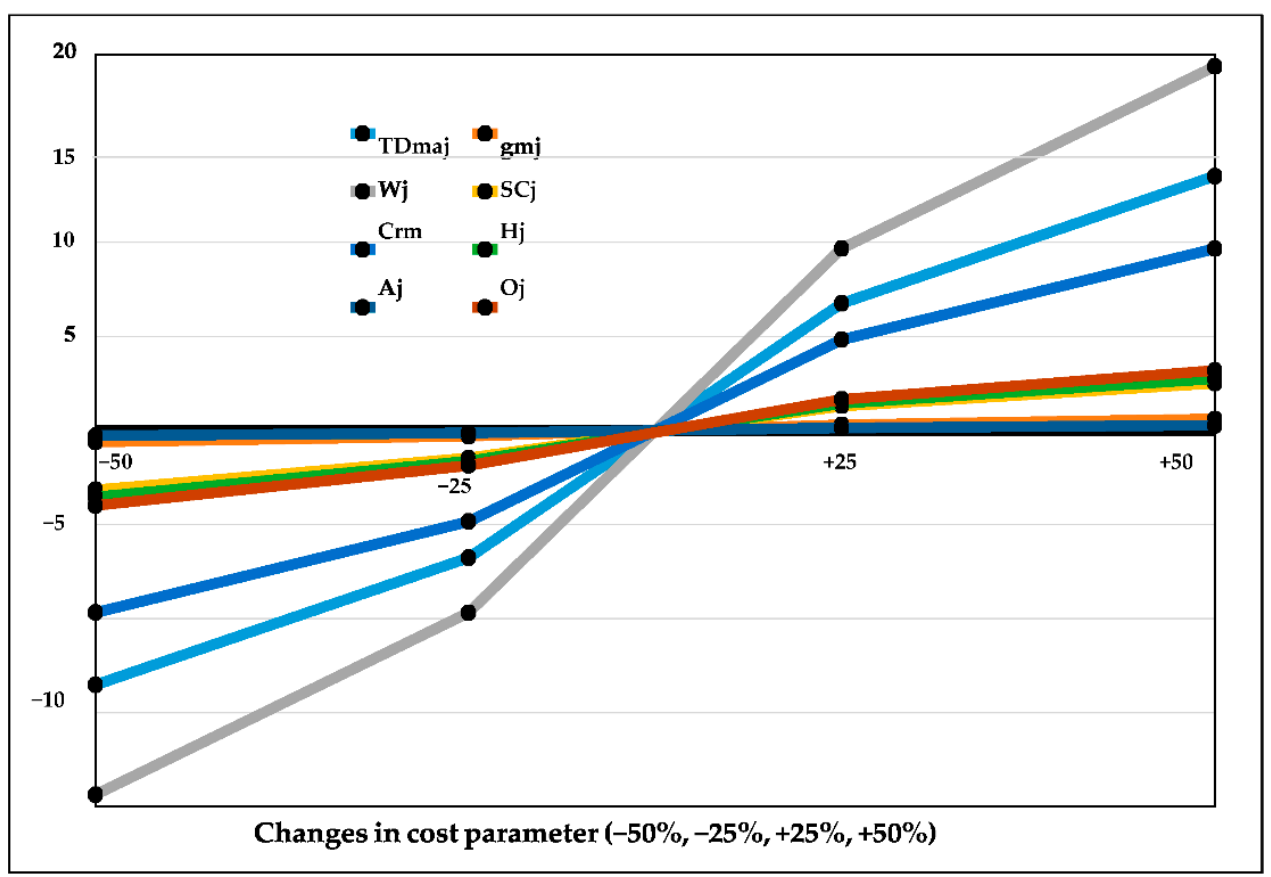

Figure 2. The sensitivity of total cost of Agri-SCM with respect to the cost parameters. 


\section{Conclusions}

Agri-production is intrinsically connected with several uncertain sources, mainly the demand patterns and production yields. From the viewpoint of sugar-cane supply chain planning, few contributions take on tactical and strategic decisions. This paper proposes an optimization model for sugarcane supply chain planning, integrating several agricultural decisions from a strategic-tactical planning perspective. Uncertainties implicate surges in demand which need to be tackled by a variable production supply chain. Indeed, technology development has enforced the agri-business stakeholders to rethink strategies and adopt a better, eco-friendly production environment with optimized costs. Despite high tech procedures, intelligent systems are an hour of need, and this work has proposed an efficient human-machine interactive model embedded, thus going a step ahead for greener production. Further, scrap and reworked products are also dealt with in the model. The right decision at the right time will lead the agricultural industry towards intelligent and smart systems. The study is a form of strategic management approach for the traders, logistics, retailers, manufacturers in agri-SCM to manage resources and to control carbon emissions for cleaner production.

In this work, a non-derivative technique is designed to integrate an algebraic approach in the agri-product based supply chain to optimize the resources and coup with variable demands through a controllable production rate. The analysis is providing a platform for manufacturing managers to invest in favor of advanced technology in agri-SCM, which ultimately leads to a less rejection production environment for clean manufacturing. The solution methodology of the proposed model included manufacturing limitations in the integration of the objective formulations with the developed system. Results findings and sensitivity analysis. The focus of these analyses is to evaluate sensitivity for an optimal solution to the value of uncertain parameters, providing confidence in the solution of the model. Managerial insights are largely beneficial to agri-SCM for the agri-food processing industry and to the people with cleaner production and carbon emission prioritized policies.

The research work can be extended into a three-echelon agri-SCM model by considering the farming industry and agri-retailer. The uncertain factors in the form of costs, prices, inflation, and time value can be dealt with using the fuzzy set theorems. The deterministic model can be converted into probabilistic or stochastic theorems for the implication of real scenarios. Overall, the agri-product supply chain needs be developed globally to make food more secure and accessible.

Author Contributions: Conceptualization, M.A. and M.O.; methodology, M.A and Q.S.K.; software, Q.S.K.; validation, M.A. and Q.S.K.; formal analysis, M.A and G.H.; investigation, G.H and B.S.; data curation, M.O and G.H.; writing—original draft preparation, M.A.; writing—review and editing, Q.S.K and B.S.; supervision, B.S.; funding acquisition, M.A. All authors have read and agreed to the published version of the manuscript.

Funding: This work was supported by Researchers Supporting Project Number (RSP-2020/274), King Saud University, Riyadh, Saudi Arabia.

Acknowledgments: The work was supported by Researchers Supporting Project Number (RSP-2020/274), King Saud University, Riyadh, Saudi Arabia. The authors are also thankful to University of Engineering and Technology, Peshawar and GIK Institute for providing necessary technical assistance.

Conflicts of Interest: The authors declare no conflict of interest.

\section{Appendix A. Model Notation}

The list of notation for agri-processing firm and vendor are given in the form of indices, decision variables, manufacturer, and vendor parameters.

\section{Indices}

$\mathrm{J}$ the index used to indicate number of agri-product, $j=1,2, \ldots \mathrm{n}$

a to indicate the parameters for first stage of agri-processing firm

b used with the parameters of vendor

c to represent the second stage of agri-processing firm

$\mathrm{m}$ used for agri-processing firm

o used for vendor 


\section{Decision Variables}

$\mathrm{Tj} \quad$ cycle time to process $\mathrm{jth}$ agri-product (units)

Lja labors utilized at 1 st stage to process $j$ th agri-product (workers)

Ljc labors utilized to process jth agri-product at 1st during final stage (workers)

Kja number of machine units utilized at 1st stage to process jth agri-product (workstations)

Kjc number of machine units utilized to process jth agri-product during finishing stage (workstations)

Pja plant production rate of jth product at 1st stage (units/year)

Pjc plant production rate of jth agri-product by the 2nd stage of agri-processing firm (units/year)

\section{Agri-Processing Parameters}

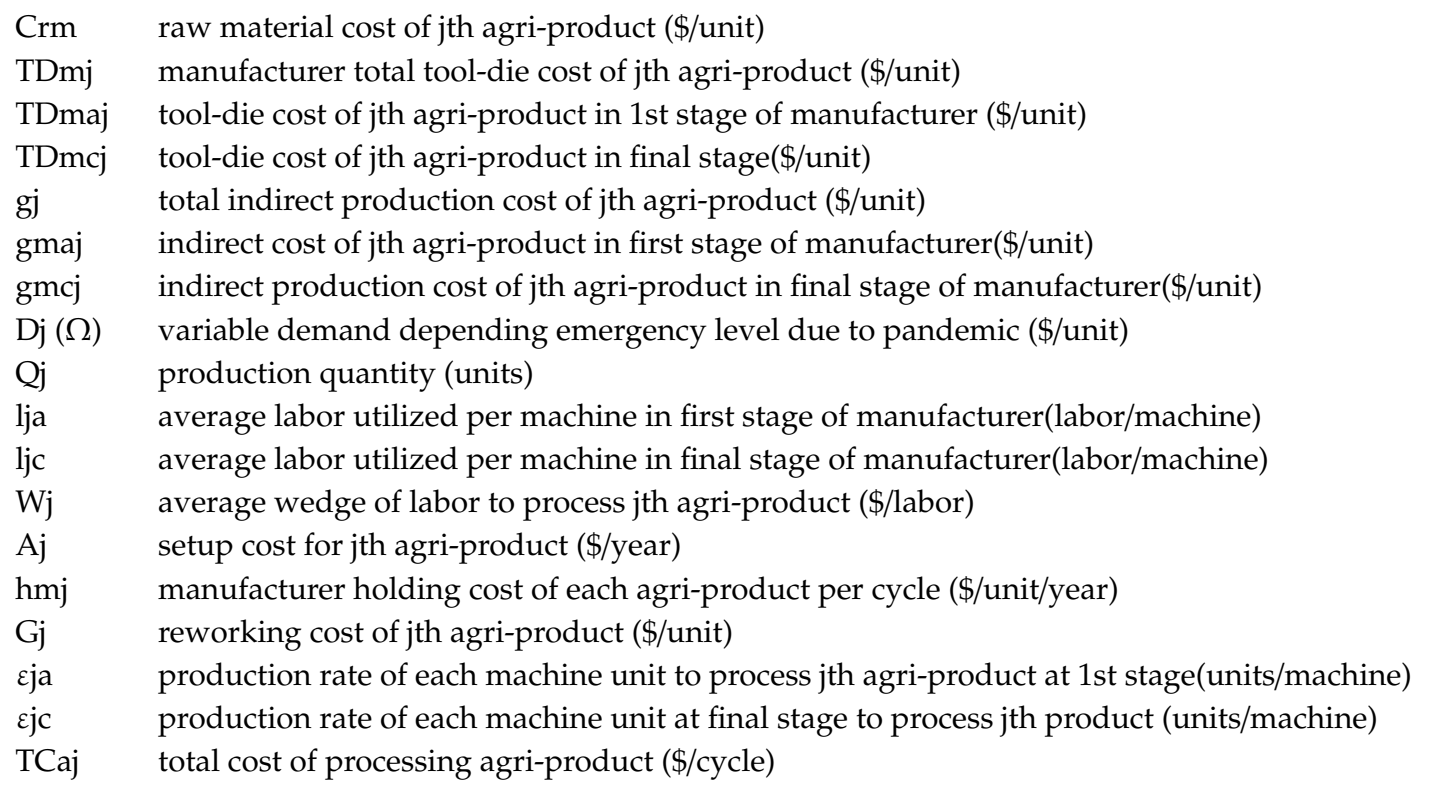

\section{Vendor Parameters}

TDoj vendor tool-die cost of jth agri-product during (\$/unit)

goj indirect part production cost of jth agri-product with vendor(\$/unit)

$\theta j \quad$ fixed inspection cost of agri-product jth (\$/year)

$\alpha j \quad$ proportion of rejection produced in defective $j$ th agri-product (\%)

$\beta \mathrm{j} \quad$ defective rate for $\mathrm{jth}$ product $(\%)$

$\psi \mathrm{j} \quad$ variable inspection cost of product jth (\$/unit)

$\gamma 1 \quad$ recycling cost (\$/unit)

$\rho \quad$ efficiency of the labor (\%)

$\mathrm{Pjb} \quad$ production rate of $\mathrm{jth}$ agri-product processed by the vendor (units/year)

TCvj total cost of vendor (\$/cycle)

MR marginal rate of vendor (\$/cycle)

TCj total cost of agri-product supply chain management (\$/cycle)

\section{Appendix B. Production Cycle Time and Inventory Level Calculations}

\section{Appendix B.1. Cycle Time Calculation}

The objective of the research is to minimize the total cost of production, and the formulation of the cycle time of the production system is prerequisite to calculate the total cost (TC). Cycle time is taken as a decision variable in the production model, which is dependent upon the production rates of manufacturing system. The production rate of the manufacturing firm and vendor are relying on the production rate of the machines (capital units). In order to meet the customer demand and no shortages in the production system, the production rates of the manufacturing system is different in the manufacturing before outsourcing, during outsourcing and after outsourcing operations are 
denoted as $P_{j a}, P_{j b}$, and $P_{j c}$ respectively. The total production cycle time of the item is the sum of the time utilized in production, outsourcing, reworking and delivery as expressed as in Equation (A1).

$$
T_{j}=t_{1 j}+t_{2 j}+t_{3 j}+t_{4 j}+t_{5 j}
$$

where, the individual time fractions of the total cycle time are mathematically formulated as given from Equations (A2) to (A6).

$$
\begin{gathered}
t_{1 j}=\frac{Q_{j}}{P_{j a}} \\
t_{2 j}=\frac{Q_{j}}{P_{j b}} \\
t_{3 j}=\frac{Q_{j} \alpha_{j}}{P_{j b}} \\
t_{4 j}=\frac{Q_{j}}{P_{j c}} \\
t_{5 j}=\frac{I_{\max (j c)}}{D_{j}}
\end{gathered}
$$

To find the value of $I_{\max (j c)}$ from the inventory diagram, the formula of slope in the Area $_{10,11,12}$ can be expressed as in Equation (A7).

$$
\begin{gathered}
\tan \theta_{4}=P_{j c}-D_{j} \Rightarrow \frac{I_{m a x}(j c)}{t_{4 j}} \\
I_{\max (j c)}=\left(P_{j c}-D_{j}\right) \frac{Q_{j}}{P_{j c}}=Q_{j}\left(1-\frac{D_{j}}{P_{j c}}\right)
\end{gathered}
$$

By putting the value of $I_{\max (j c)}$, the simplified form of Equation (A6) can be expressed as in Equation (A10).

$$
\begin{gathered}
t_{5 j}=\frac{Q_{j}\left(1-\frac{D_{j}}{P_{j c}}\right)}{D_{j}} \\
t_{5 j}=Q_{j}\left(\frac{1}{D_{j}}-\frac{1}{P_{j c}}\right)
\end{gathered}
$$

After calculating all the time fractions $\left(t_{1 j}\right.$ to $t_{5 j}$ ) for the production of automobile parts, the mathematical form of the total cycle time can be given as in Equation (A11).

$$
T_{j}=\frac{Q_{j}}{P_{j a}}+\frac{Q_{j}}{P_{j b}}+\frac{Q_{j} \alpha_{j}}{P_{j b}}+\frac{Q_{j}}{P_{j c}}+Q_{j}\left(\frac{1}{D_{j}}-\frac{1}{P_{j c}}\right)
$$

Appendix B.2. Average Inventory Costs

The inventory is obtained by calculating the area under the curve of the production, storage, and buffer quantity in complete manufacturing process. As followed the inventory diagram given as in Figure 2, the inventories can be divided into the areas i.e., Area ${ }_{123}$, Area $_{456}$, Area $_{5678}$, Area $_{10,11,12}$, and $A r e a_{11,12,13}$. These areas are formulated separately from Equation (A12) to Equation (A26) respectively.

$$
\begin{gathered}
\operatorname{Area}_{123}=\frac{1}{2} t_{1 j} I_{\max (j a)} \\
\tan \theta_{1}=\frac{I_{\max (j a)}}{t_{1 j}} P_{j a} \times t_{1 j}=I_{\max (j a)} I_{\max (j a)}=Q_{j}
\end{gathered}
$$


By putting $I_{\max (j a)}$, Equation (A12) can be written as in Equation (A14).

$$
\operatorname{Area}_{123}=\frac{Q_{j}^{2}}{2 P_{j a}}
$$

Similarly, the area of triangle 456 can be given as in Equation (A15)

$$
\operatorname{Area}_{456}=\frac{1}{2} I_{\max (j b b)} t_{2 j}
$$

The maximum inventory of the vendor $I_{\max (j b b)}$ is calculated by the slope formula of Area 456 (Equation (A16)), which is then simplified to express in the form of Equation (A17)

$$
\begin{gathered}
\tan \theta_{2}=\frac{I_{\max (j b b)}}{t_{2 j}} \\
P_{j b}\left(1-\alpha_{j}\right) \times \frac{Q_{j}}{P_{j b}}=I_{\max (j b b)} I_{\max (j b b)}=Q_{j}\left(1-\alpha_{j}\right)
\end{gathered}
$$

After substituting, the Area $_{456}$ can be written as in Equation (A18)

$$
\text { Area }_{456}=\frac{1}{2} Q_{j}\left(1-\alpha_{j}\right) \frac{Q_{j}}{P_{j b}} \text { Area }_{456}=\frac{Q_{j}^{2}\left(1-\alpha_{j}\right)}{2 P_{j b}}
$$

The simplified form of area under the curve of the rectangular region 5678 is formulated and expressed as in Equation (A19)

$$
\operatorname{Area}_{5678}=I_{\max (j b b)} t_{3 j}=Q_{j}\left(1-\alpha_{j}\right) \frac{Q_{j} \alpha_{j}}{P_{j b}}=\frac{\alpha_{j}\left(1-\alpha_{j}\right) Q_{j}^{2}}{P_{j b}}
$$

The triangular area of the inventory storage Area $_{689}$ by reworking operations during outsourcing operation is expressed as in Equation (A20).

$$
\text { Area }_{689}=\frac{1}{2} I_{m a x}(j b a) t_{3 j}
$$

where, to find the maximum inventory $I_{\max (j b a)}$ of the reworking operation in the production system, the slope formula is given as in Equation (A21),

$$
\tan \theta_{3}=\frac{I_{\max (j b a)}}{t_{3 j}} P_{j b}\left(1-\alpha_{j} \beta_{j}\right) \frac{Q_{j} \alpha_{j}}{P_{j b}}=I_{\max (j b a)} I_{\max (j b a)}=\alpha_{j} Q_{j}\left(1-\alpha_{j} \beta_{j}\right)
$$

By substitution, Equation (A20) can be written in the form of Equation (A22).

$$
\text { Area }_{689}=\frac{1}{2} \frac{Q_{j} \alpha_{j}}{P_{j b}} \alpha_{j} Q_{j}\left(1-\alpha_{j} \beta_{j}\right)=\frac{\alpha_{j}^{2} Q_{j}^{2}\left(1-\alpha_{j} \beta_{j}\right)}{2 P_{j b}}
$$

Likewise, the Area $_{10,11,12}$ and Area $_{11,12,13}$ can be formulated and expressed in simplified form as in Equations (A25) and (A26) respectively, where the maximum inventory is $I_{\max (j c)}$.

$$
\begin{gathered}
\operatorname{Area}_{10,11,12}=\frac{1}{2} I_{\max (j c)} t_{4 j} \\
\tan \theta_{4}=P_{j c}-D_{j} \Rightarrow \frac{I_{\max (j c)}}{t_{4 j}} I_{\max (j c)}=\left(P_{j c}-D_{j}\right) \frac{Q_{j}}{P_{j c}}
\end{gathered}
$$




$$
\begin{gathered}
\operatorname{Area}_{10,11,12}=\frac{1}{2} Q_{j}\left(1-\frac{D_{j}}{P_{j c}}\right) \frac{Q_{j}}{P_{j c}} \\
\text { Area }_{11,12,13}=\frac{1}{2} I_{\max (j c)} t_{5 j}=\frac{1}{2} \frac{I_{\max (j c)}^{2}}{D_{j}}=\frac{Q_{j}^{2}}{2 D_{j}}\left(1-\frac{D_{j}}{P_{j c}}\right)^{2}
\end{gathered}
$$

\section{References}

1. Banasik, A.; Kanellopoulos, A.; Bloemhof-Ruwaard, J.M.; Claassen, G.D.H. Accounting for uncertainty in eco-efficient agri-food supply chains: A case study for mushroom production planning. J. Clean. Prod. 2019, 216, 249-256. [CrossRef]

2. Thron, T.; Nagy, G.; Wassan, N. Evaluating alternative supply chain structures for perishable products. Int. J. Logist. Manag. 2007, 18, 364-384. [CrossRef]

3. Chen, W.; Li, J.; Jin, X. The replenishment policy of agri-products with stochastic demand in integrated agricultural supply chains. Expert Syst. Appl. 2016, 48, 55-66. [CrossRef]

4. Cobb, B.R.; Rumí, R.; SalmeróN, A. Inventory management with log-normal demand per unit time. Comput. Oper. Res. 2013, 40, 1842-1851. [CrossRef]

5. Alexandratos, N.; Bruinsma, J. World Agriculture towards 2030/2050: The 2012 Revision. 2012. Available online: http://www.fao.org/fileadmin/templates/esa/Global_persepctives/ (accessed on 19 April 2020).

6. Drozda, T.J. Tool and Manufacturing Engineers Handbook: Machining; Society of Manufacturing Engineers: Dearborn, Michigan, 1983; Volume 1.

7. Conrad, C.; McClamroch, N. The drilling problem: A stochastic modeling and control example in manufacturing. IEEE Trans. Autom. Control 1987, 32, 947-958. [CrossRef]

8. Khouja, M. The economic production lot size model under volume flexibility. Comput. Oper. Res. 1995, 22, 515-523. [CrossRef]

9. Offodile, O.F.; Ugwu, K. Evaluating the effect of speed and payload on robot repeatability. Robot. Comput. Integr. Manuf. 1991, 8, 27-33. [CrossRef]

10. Mehrez, A.; Offodile, O.F.; Ahm, B.-H. A decision analysis view of the effect of robot repeatability on profit. IIE Trans. 1995, 27, 60-71. [CrossRef]

11. Chaabane, A.; Ramudhin, A.; Paquet, M. Designing supply chains with sustainability considerations. Prod. Plan. Control 2011, 22, 727-741. [CrossRef]

12. Neto, J.Q.F.; Walther, G.; Bloemhof, J.; van Nunen, J.A.E.E.; Spengler, T. A methodology for assessing eco-efficiency in logistics networks. Eur. J. Oper. Res. 2009, 193, 670-682. [CrossRef]

13. El Yasmine, A.S.L.; Ghani, B.A.; Trentesaux, D.; Bouziane, B. Supply chain management using multi-agent systems in the agri-food industry. In Service Orientation in Holonic and Multi-Agent Manufacturing and Robotics; Springer: Berlin/Heidelberg, Germany, 2014; pp. 145-155.

14. Zecca, F.; Rastorgueva, N. Supply chain management and sustainability in agri-food system: Italian evidence. J. Nutr. Ecol. Food Res. 2014, 2, 20-28. [CrossRef]

15. Biswas, P.; Sarker, B.R. Optimal batch quantity models for a lean production system with in-cycle rework and scrap. Int. J. Prod. Res. 2008, 46, 6585-6610. [CrossRef]

16. Tayyab, M.; Sarkar, B. Optimal batch quantity in a cleaner multi-stage lean production system with random defective rate. J. Clean. Prod. 2016, 139, 922-934. [CrossRef]

17. Omair, M.; Sarkar, B.; Cárdenas-Barrón, L.E. Minimum quantity lubrication and carbon footprint: A step towards sustainability. Sustainability 2017, 9, 714. [CrossRef]

18. Kwak, M. Planning demand-and legislation-driven remanufacturing for a product family. Ind. Eng. Manag. Syst. 2015, 14, 159-174.

19. Xiao, Y.; Yang, S.; Zhang, L.; Kuo, Y.-H. Supply chain cooperation with pricesensitive demand and environmental impacts. Sustainability 2016, 8, 716. [CrossRef]

20. Wu, C.-C.; Chang, N.-B. Corporate optimal production planning with varying environmental costs: A grey compromise programming approach. Eur. J. Oper. Res. 2004, 155, 68-95. [CrossRef]

21. Wang, F.; Lai, X.; Shi, N. A multi-objective optimization for green supply chain network design. Decis. Support Syst. 2011, 51, 262-269. [CrossRef] 
22. Wang, E.-J.; Lin, C.-Y.; Su, T.-S. Electricity monitoring system with fuzzy multiobjective linear programming integrated in carbon footprint labeling system for manufacturing decision making. J. Clean. Prod. 2016, 112, 3935-3951. [CrossRef]

23. Goyal, S.K.; Cárdenas-Barrón, L.E. Note on: Economic production quantity model for items with imperfect quality-A practical approach. Int. J. Prod. Econ. 2002, 77, 85-87. [CrossRef]

24. Wee, H.M.; Yu, J.; Chen, M.C. Optimal inventory model for items with imperfect quality and shortage backordering. Omega 2007, 35, 7-11. [CrossRef]

25. Hsu, W.-K.K.; Yu, H.-F. EOQ model for imperfective items under a one-time-only discount. Omega 2009, 37, 1018-1026.

26. Sarkar, S.; Giri, B.C. Stochastic supply chain model with imperfect production and controllable defective rate. Int. J. Syst. Sci. Oper. Logist. 2020, 7, 133-146. [CrossRef]

27. Sarkar, B.; Ahmed, W.; Kim, N. Joint effects of variable carbon emission cost and multi-delay-in-payments under single-setup-multiple-delivery policy in a global sustainable supply chain. J. Clean. Prod. 2018, 185, 421-445. [CrossRef]

28. Tiwari, S.; Ahmed, W.; Sarkar, B. Multi-item sustainable green production system under trade-credit and partial backordering. J. Clean. Prod. 2018, 204, 82-95. [CrossRef]

29. Khouja, M.; Mehrez, A. Economic production lot size model with variable production rate and imperfect quality. J. Oper. Res. Soc. 1994, 45, 1405-1417. [CrossRef]

30. Rosenblatt, M.J.; Lee, H.L. Economic production cycles with imperfect production processes. IIE Trans. 1986, 18, 48-55. [CrossRef]

31. Khouja, M. A note on 'deliberately slowing down output in a family production context'. Int. J. Product. Res. 1999, 37, 4067-4077. [CrossRef]

32. Eiamkanchanalai, S.; Banerjee, A. Production lot sizing with variable production rate and explicit idle capacity cost. Int. J. Prod. Econ. 1999, 59, 251-259. [CrossRef]

33. Giri, B.C.; Yun, W.Y.; Dohi, T. Optimal design of unreliable production-Inventory systems with variable production rate. Eur. J. Oper. Res. 2005, 162, 372-386. [CrossRef]

34. Larsen, C. The economic production lot size model extended to include more than one production rate. Int. Trans. Oper. Res. 2005, 12, 339-353. [CrossRef]

35. Sana, S.S. A production-inventory model in an imperfect production process. Eur. J. Oper. Res. 2010, 200, 451-464. [CrossRef]

36. Ayed, S.; Sofiene, D.; Nidhal, R. Joint optimisation of maintenance and production policies considering random demand and variable production rate. Int. J. Prod. Res. 2012, 50, 6870-6885. [CrossRef]

37. Bouslah, B.; Gharbi, A.; Pellerin, R. Joint optimal lot sizing and production control policy in an unreliable and imperfect manufacturing system. Int. J. Prod. Econ. 2013, 144, 143-156. [CrossRef]

38. Singh, S.; Prasher, L. A production inventory model with flexible manufacturing, random machine breakdown and stochastic repair time. Int. J. Ind. Eng. Comput. 2014, 5, 575-588. [CrossRef]

39. Zanoni, S.; Bettoni, L.; Glock, C.H. Energy implications in a two-stage production system with controllable production rates. Int. J. Prod. Econ. 2014, 149, 164-171. [CrossRef]

40. Linde-Rahr, M. Rural Shadow Wages, Labour Supply and Agricultural Production under Imperfect Markets: Empirical Evidence from Vietnam. Labor Hum. Cap. 2001, 31. Available online: http://ageconsearch.umn. edu/record/20487 (accessed on 26 April 2020). [CrossRef]

41. Sarkar, B.; Moon, I. An EPQ model with inflation in an imperfect production system. Appl. Math. Comput. 2011, 217, 6159-6167. [CrossRef]

42. Sana, S.S. A production-inventory model of imperfect quality products in a threelayer supply chain. Decis. Support Syst. 2011, 50, 539-547. Available online: http://www.sciencedirect.com/science/article/pii/ S0167923610001934 (accessed on 2 May 2020). [CrossRef]

43. Sarkar, B.; Majumder, A.; Sarkar, M.; Dey, B.K.; Roy, G. Two-echelon supply chain model with manufacturing quality improvement and setup cost reduction. J. Ind. Manag. Optim. 2017, 13, 1085. [CrossRef]

44. Ma, X.; Wang, S.; Islam, S.M.N.; Liu, X. Coordinating a threeechelon fresh agricultural products supply chain considering freshness-keeping effort with asymmetric information. Appl. Math. Model. 2019, 67, 337-356. Available online: http://www.sciencedirect.com/science/article/pii/S0307904X18305201 (accessed on 30 April 2020). [CrossRef] 
45. Yang, J.; Qi, X.; Xia, Y. A production-inventory system with markovian capacity and outsourcing option. Oper. Res. 2005, 53, 328-349. [CrossRef]

46. Wang, Y.; Niu, B.; Guo, P. On the advantage of quantity leadership when outsourcing production to a competitive contract manufacturer. Prod. Oper. Manag. 2013, 22, 104-119. [CrossRef]

47. Bettayeb, B.; Bassetto, S.J.; Sahnoun, M. Quality control planning to prevent excessive scrap production. J. Manuf. Syst. 2014, 33, 400-411. [CrossRef]

48. AlDurgam, M.; Adegbola, K.; Glock, C.H. A single-vendor single-manufacturer integrated inventory model with stochastic demand and variable production rate. Int. J. Prod. Econ. 2017, 191, 335-350. [CrossRef]

49. Sarkar, B.; Majumder, A.; Sarkar, M.; Kim, N.; Ullah, M. Effects of variable production rate on quality of products in a single-vendor multi-buyer supply chain management. Int. J. Adv. Manuf. Technol. 2018, 99, 567-581. [CrossRef]

50. Sarkar, B. An inventory model with reliability in an imperfect production process. Appl. Math. Comput. 2012, 218, 4881-4891. Available online: http://www.sciencedirect.com/science/article/pii/S0096300311012999 (accessed on 15 April 2020). [CrossRef]

51. Bazan, E.; Jaber, M.Y; Zanoni, S. Supply chain models with greenhouse gases emissions, energy usage and different coordination decisions. Appl. Math. Model. 2015, 39, 5131-5151. [CrossRef]

52. Mansour, M. Quantifying the intangible costs related to non-ergonomic work conditions and work injuries based on the stress level among employees. Saf. Sci. 2016, 82, 283-288. [CrossRef]

53. Omair, M.; Ullah, M.; Ganguly, B.; Noor, S.; Maqsood, S.; Sarkar, B. The quantitative analysis of workers' stress due to working environment in the production system of the automobile part manufacturing industry. Mathematics 2019, 7, 627. [CrossRef]

Publisher's Note: MDPI stays neutral with regard to jurisdictional claims in published maps and institutional affiliations. 